\section{A) Check for updates}

Cite this: Green Chem., 2020, 22 2443

Received 21st June 2019, Accepted 9th December 2019 DOI: $10.1039 /$ c9gc02088h rsc.li/greenchem

\title{
Solvent-free hydrogenation of levulinic acid to $\gamma$-valerolactone using a Shvo catalyst precursor: optimization, thermodynamic insights, and life cycle assessment $\uparrow$
}

\author{
Christian A. M. R. van Slagmaat, (D) Marie A. F. Delgove, (D) Jules Stouten, \\ Lukas Morick, $\$$ Yvonne van der Meer, (D) * Katrien V. Bernaerts (D) and \\ Stefaan M. A. De Wildeman (D) *
}

\begin{abstract}
The hydrogenation of levulinic acid (LA) to $\gamma$-valerolactone (GVL) using the $\eta^{4}$-(2,3,4,5-tetraphenylcyclopentadienone) ruthenium tricarbonyl precursor of the well-known Shvo catalyst and $\mathrm{H}_{2}$ pressure was established under solvent-free conditions to achieve 100\% conversion and $100 \%$ selectivity within 5 hours. Kinetic reaction curves were measured in order to deduce the optimal reaction conditions, which were further evaluated by means of density functional theory (DFT) calculations, and compared with catalytic concepts that consume formic acid or isopropyl alcohol as hydrogen donor. Ultimately, this alternative reaction procedure was subjected to a life cycle assessment (LCA) in comparison with the transfer hydrogenation methodologies, in order to verify its contribution towards a practice of environmentally benign chemistry.
\end{abstract}

\section{Introduction}

While for the past 150 years many of our fuel, drug, and material needs have been satisfied with fossil-based products, the need to find sustainable bio-based alternatives is everincreasing with dwindling resources, accelerating global warming, and increasing global turmoil. ${ }^{1}$ One promising source of such renewable resources is the abundant and widely accessible lignocellulosic material. Much effort over the past decades has gone into the development of technologies to harness the potential of this inherently complex natural material, and cellulose in particular has become an efficient feedstock to produce a large variety of building blocks and fuels. ${ }^{2}$ Many processes such as fermentation, enzymatic depolymerizations, and acid-catalyzed conversions have become well established in providing mono-sugars or oligomers, which in turn can be transformed further into numerous fine chemicals. $^{3}$

Department of Biobased Materials, Aachen-Maastricht Institute for Biobased Materials, Maastricht University, Brightlands Chemelot Campus, 6167 RD Geleen, The Netherlands. E-mail: c.vanslagmaat@maastrichtuniversity.nl,

yvonne.vandermeer@maastrichtuniversity.nl,s.dewildeman@maastrichtuniversity.nl; https://wuw.maastrichtuniversity.nl/research/department-biobased-materials

$\dagger$ Electronic supplementary information (ESI) available. See DOI: 10.1039/ c9gc02088h

$\$$ These authors contributed equally to this work.
In 2004, the US Department of Energy compiled a list of promising substrates obtainable from carbohydrates, categorizing them according to their anticipated properties in one of nine different fields. ${ }^{4}$ LA is one of those molecules, that was identified as a platform molecule showing great potential for a large variety of conversions. ${ }^{5}$ It is shown to be facilely convertible into molecules relevant in a plethora of different applications (Scheme 1). One conversion is particularly relevant in the fields of bio-based solvents, ${ }^{6}$ fuels, ${ }^{7}$ and fuel additives: ${ }^{8}$ the hydrogenation of LA to GVL. In addition, other research identifies the high potential of this molecule as monomer for the synthesis of polymeric materials ${ }^{9}$ and related applications, such as the conversion to adipic acid via (hydroxy) carbonylation with carbon monoxide or formic acid (FA). The high value of adipic acid in polycondensations creates high interest in this conversion. ${ }^{10}$ In terms of domestic applications (e.g. cosmetical products, ${ }^{11}$ lighter- and candle fluids ${ }^{7}$ ), beneficial properties of GVL are its high thermal and chemical stability, ${ }^{12}$ and its pleasant smell. ${ }^{11}$ GVL also possesses a stereogenic carbon center, which creates opportunities for the manufacture of pharmaceutical products, should enantio-selectivity be achieved. ${ }^{13}$

Over the last couple of decades, various catalytic procedures have been established for the hydrogenation of LA to GVL. ${ }^{14}$ Heterogeneous catalysts are often preferred in chemical industries for advantages, such as facile separation and recycling. However, various homogeneous catalysts recently have entered the spotlights by displaying high activities and excellent - or at 


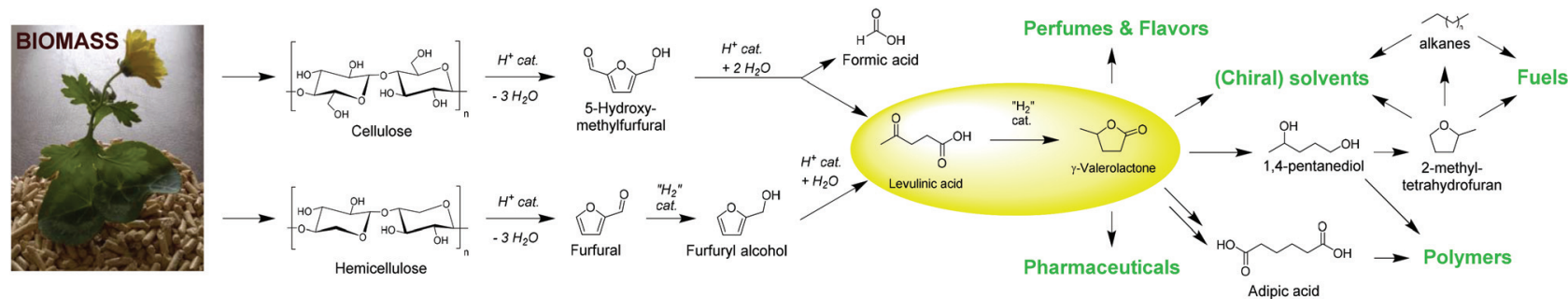

Scheme 1 Overview of the conversion of biomass via (hemi)cellulose, furanoic platform molecules, and LA into GVL, and its various applications.

least tunable - selectivity towards GVL. Among the homogeneous examples some outstanding turn-over numbers (TON) up to 174000 have been reported for catalysts based on ruthenium $^{15}$ and iridium ${ }^{16}$ predominantly, while iron ${ }^{17}$ has recently made its debut.

Other homogeneous catalysts have also shown tolerance to solvent-free conditions. Several in situ catalysts derived from $\mathrm{Ru}(\mathrm{acac})_{3}$ and phosphine ligands were shown to be highly efficient by the groups of Horváth, ${ }^{18}$ Leitner, ${ }^{19}$ Mika, ${ }^{15 a, 20}$ and Beller, ${ }^{15 b}$ whereas full conversions to GVL were selectively achieved under 80-100 bar $\mathrm{H}_{2}$ pressure and temperatures of 135-160 ${ }^{\circ} \mathrm{C}$. Alternatively, Deng et al. reported the transfer hydrogenation of LA using 1 equivalent of FA catalyzed by $\mathrm{RuCl}_{3}$ with phosphine ligands. ${ }^{21}$ Other examples of transfer hydrogenation using FA in slight excess (less than 2 equivalents) were demonstrated with Shvo-type catalysts at a milder temperature of $100{ }^{\circ} \mathrm{C}$ by Fábos et al., ${ }^{22}$ and with dipyridyl-ligated ruthenium $^{23}$ and iridium ${ }^{16 c, 23}$ catalysts by Wang et al. Moreover, the group of Makhubela recently reported ruthenium catalysts with pyrazolylphosphite ${ }^{24}$ and pyridylimine ${ }^{25}$ ligands, of which the former one is able to use both FA and $\mathrm{H}_{2}$ as hydrogen donors in low quantities of 1 equivalent and 5-20 bar, respectively, for this conversion. The same group also synthesized polynuclear $\mathrm{Ru}_{4}{ }^{\wedge} \mathrm{Zn}_{2}$ complexes with phosphino-carboxylate ligands, which show a remarkably improved activity for such transfer hydrogenations compared to their corresponding monomeric forms. ${ }^{26}$

Previously, we reported on the comparative study of the Shvo catalyst versus its pre-activated iron analogue, the acetonitrile-appended Knölker catalyst, for the selective hydrogenation of LA to GVL. ${ }^{27}$ Herein, the catalysis was driven by the hydrogen donors isopropyl alcohol (IPA) and $\mathrm{H}_{2}$ in various solvents. Although appreciable TON's could be achieved by using the iron catalyst, the ruthenium Shvo catalyst was significantly more active. However, the solvent-free form of this chemical transformation using $\mathrm{H}_{2}$ reductant facilitated by the Shvo catalyst is not reported yet, and the absence of added organic solvents herein are envisioned as key to furtherly improve spacetime yields significantly, and thereby also reducing the environmental impact of the process. While in transfer hydrogenation the hydrogen donor (e.g. FA, IPA) often co-functions as a solvent and therefore may stabilize the in situ catalytic species, ${ }^{28}$ the use of $\mathrm{H}_{2}$ under absolute solvent-free conditions is expected to be more challenging. Meanwhile, the use of $\mathrm{H}_{2}$ does not yield any by-products, unlike FA and IPA, which co- produce stoichiometric amounts of carbon dioxide $\left(\mathrm{CO}_{2}\right)$ and acetone, respectively. Hence, it is expected that this chemical route is environmentally more benign. Furthermore, $\mathrm{H}_{2}$ allows more parameter variation (temperature, pressure) without diminishing the effective reaction volume. On the other hand, using FA as reductant is an eclectic choice as well, since FA is the co-product of the synthesis of LA from 5-hydroxymethylfurfural (HMF) (Scheme 1), and would not require separation before a subsequent hydrogenation step. Hence, we questioned how the choice of hydrogen donor under solvent-free conditions affects the reaction in terms of catalytic performance as well as environmental impact.

Therefore, we established the solvent-free $\mathrm{H}_{2}$-mediated selective hydrogenation of LA to GVL using the monomeric Shvo catalyst precursor Ru-1 in this work, and optimized it in terms of temperature, $\mathrm{H}_{2}$-pressure, and catalyst loading. A possibility for catalyst recycling as well as the role of water in the catalytic mechanism were investigated. Computational DFT experiments were conducted to evaluate the thermodynamic pathways of different hydrogen donors, and these results were validated with the experimental observations. Finally, a LCA evaluating the use of each hydrogen donor in this context was performed.

\section{Results and discussion}

\subsection{Catalyst precursor syntheses and evaluation in catalysis}

To pursue our findings regarding the activity of the Shvo-type ruthenium catalysts, it was decided to test all three possible precursors. These can be synthesized from triruthenium dodecacarbonyl and tetraphenylcyclopentadienone in refluxing toluene, methanol, or heptane, to yield the monomeric $\left[2,3,4,5-\mathrm{Ph}_{4}\left(\eta^{4}-\mathrm{C}_{4} \mathrm{CO}\right)\right] \mathrm{Ru}(\mathrm{CO})_{3}(\mathbf{R u}-\mathbf{1})$, and the dimeric species $\left\{\left[2,3,4,5-\mathrm{Ph}_{4}\left(\eta^{4}-\mathrm{C}_{4} \mathrm{CO}\right)\right]_{2} \mathrm{H}\right\} \mathrm{Ru}_{2}(\mathrm{CO})_{4}-(\mu-\mathrm{H})(\mathbf{R u}-2)$ and $\{[2,3,4,5-$ $\left.\left.\mathrm{Ph}_{4}\left(\eta^{4}-\mathrm{C}_{4} \mathrm{CO}\right)\right] \mathrm{Ru}(\mathrm{CO})_{2}\right\}_{2} \quad(\mathbf{R u}-3)$, respectively (Scheme 2, 'Synthesis'). ${ }^{29}$ High yields up to $98 \%$ for Ru-1 were typically obtained, since this compound can facilely be purified using column chromatography. However, Ru-2 and Ru-3 require precipitation/crystallization in order to be isolated, leading to lower yields in the range of $50-60 \%$ in our hands.

Exploratory hydrogenation reactions of LA using these catalyst precursors were conducted under solvent-free conditions at $100{ }^{\circ} \mathrm{C}$ and under 50 bar $\mathrm{H}_{2}$ pressure for 5 hours. 


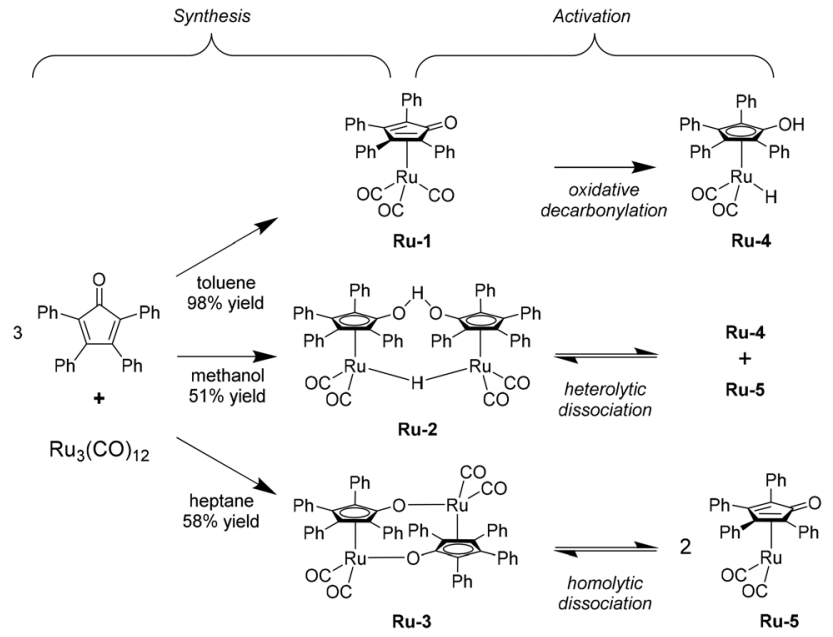

Scheme 2 Overview for the solvent-mediated syntheses of the three different Shvo catalyst precursors and their dissociation into the catalytically active species. Each synthetic pathway requires reflux conditions under a $\mathrm{N}_{2}$ atmosphere during $24-72$ hours.

The control experiments employing no catalytic additive; only the ligand; only $\mathrm{Ru}_{3}(\mathrm{CO})_{12}$; and the ligand plus $\mathrm{Ru}_{3}(\mathrm{CO})_{12}$ (Table 1, entries 1-4, respectively) all rendered no conversions, while significant activity was observed for $\mathbf{R u - 1}, \mathbf{R u}-\mathbf{2}$, and $\mathbf{R u}-\mathbf{3}$ with TON's of at least 630 (Table 1, entries 5-7). This observation confirms that the sophisticated organometallic structure of the Shvo catalyst is indeed essential to afford catalytic activity in this reaction, and that in situ generation in LA is not possible. Moreover, the remarkable difference in LA conversion between Ru-1 (63\%) and both Ru-2 and Ru-3 (>99\%) can be rationalized by the requirement of mono-decarbonylation for Ru-1 in order to be activated (vide infra), while the dimeric Ru-2 and Ru-3 are reported to readily dissociate at $80^{\circ} \mathrm{C}$ into monomeric ruthenium species $\mathbf{R u - 4}$ and $\mathbf{R u - 5}$, that are part of the catalytic cycle (Scheme 2, 'Activation'). ${ }^{22}$

Table 1 Exploratory solvent-free hydrogenations of LA to GVL using the Shvo precursor catalysts and several control experiments

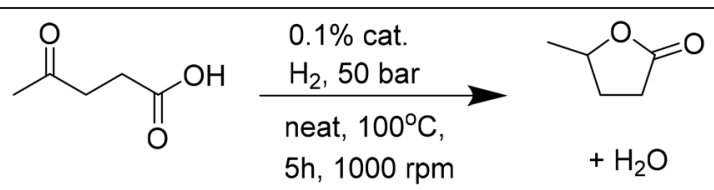

\begin{tabular}{lll}
\hline Entry $^{a}$ & Catalyst precursor & GVL yield (\%) \\
\hline 1 & None & 0 \\
$2^{b}$ & $\mathrm{Ph}_{4} \mathrm{CpO}$ ligand & 0 \\
3 & $\mathrm{Ru}_{3}(\mathrm{CO})_{12}$ & 0 \\
4 & $3 \mathrm{Ph}_{4} \mathrm{CpO}+\mathrm{Ru}_{3}(\mathrm{CO})_{12}$ & 0 \\
5 & $\mathbf{R u}-\mathbf{1}$ & 63.0 \\
6 & $\mathbf{R u}-2$ & 99.5 \\
7 & $\mathbf{R u}-3$ & 99.1 \\
8 & $\mathbf{F e}-2$ & 0
\end{tabular}

${ }^{a}$ Catalyst loading is always based on the amount of metal atoms. ${ }^{b} 0.1 \mathrm{~mol} \%$ ligand with respect to LA.
Alternatively, the structurally related iron Knölker-type catalysts could be realized as a cheaper and greener substitute. In our previous study we concluded the necessity of converting Knölker's complex (Fe-1) into its mono-decarbonylated acetonitrile-appended contender Fe-2, to conveniently afford Casey's catalyst (Fe-3) in situ for the successful hydrogenation of LA in a solvent (ESI, Scheme S1.1 $\dagger$ ). ${ }^{27}$ In this work we tested Fe-2 also under solvent-free conditions, but it rapidly decomposed as such, and no LA conversion was observed (Table 1, entry 8). Therefore, the focus was kept on the Shvo catalyst.

Despite the lower activity of Ru-1 compared to its dimeric homologues, we selected this catalyst precursor for further investigation on the basis of the synthetic yields, as well as possible future applications of Shvo type complexes with substituents on the 2- and 5-position, which are too large to allow the dimer formations seen for $\mathbf{R u - 2}$ and $\mathbf{R u}-\mathbf{3} .^{30}$ In addition, this choice gave us the opportunity to elucidate the relation between requiring in situ decarbonylation of $\mathbf{R u - 1}$ and the inhibited LA conversion (63.0\%), and how to overcome it.

\subsection{Reaction parameter optimizations}

The research was continued by establishing kinetic curves for each experiment using $0.1 \% \mathbf{R u}-\mathbf{1}$, in order to observe the effect of systematically altering the reaction conditions. These experiments took place in a batch autoclave reactor, equipped with an external heating mantle, which required 10-15 minutes to heat up the reaction mixture to the desired temperature. Since the $t=0$ point is defined as the moment where heating was initiated, the first 15 minutes of the reaction always feature minimal LA conversion.

Firstly, the reaction temperature was varied, ranging from 100 to $160{ }^{\circ} \mathrm{C}$ (Fig. 1A). While a maximal turn-over frequency (TOF) of $144 \mathrm{~h}^{-1}$ is finally reached after 3 hours at $100{ }^{\circ} \mathrm{C}$, a dramatic increase in activity was achieved at $120^{\circ} \mathrm{C}$, rendering a TOF of $598 \mathrm{~h}^{-1}$ after 30 minutes already, and reaching nearcomplete conversion within 4 hours. A further increase in activity was observed at $140{ }^{\circ} \mathrm{C}$ and $160^{\circ} \mathrm{C}$ with maximal local TOF's around $1200 \mathrm{~h}^{-1}$. However, these reactions undergo sudden catalyst deactivation after 60-90 minutes at LA conversions of $97 \%$ and $78 \%$, respectively. Thus, an optimal reaction temperature of $120{ }^{\circ} \mathrm{C}$ was found for $\mathbf{R u}-\mathbf{1}$, as in agreement with the observation of Casey et al., that decomposition of such complexes starts around $130{ }^{\circ} \mathrm{C} .{ }^{31} \mathrm{Next}$, the $\mathrm{H}_{2}$ pressure was varied from 20 to 100 bar at the optimal reaction temperature of $120{ }^{\circ} \mathrm{C}$ (Fig. 1B). In general, a higher TOF was achieved by applying a higher $\mathrm{H}_{2}$ pressure, but a ceiling in activity was observed at 50 bar $\mathrm{H}_{2}$ pressure and higher. Nevertheless, $>97 \%$ GVL yields were always obtained after 5 hours. As such, 50 bar $\mathrm{H}_{2}$ was selected as the optimal pressure for this reaction.

The concentration effect of Ru-1 was investigated as well (Fig. 1C). Higher reaction rates were observed at higher concentrations of Ru-1, as expected. However, the relative TOFs increased upon lowering the catalyst loading. In order to yield $>99 \%$ GVL within the convenient time frame of 5 hours, $0.1 \%$ Ru-1 should be maintained. 
(A)

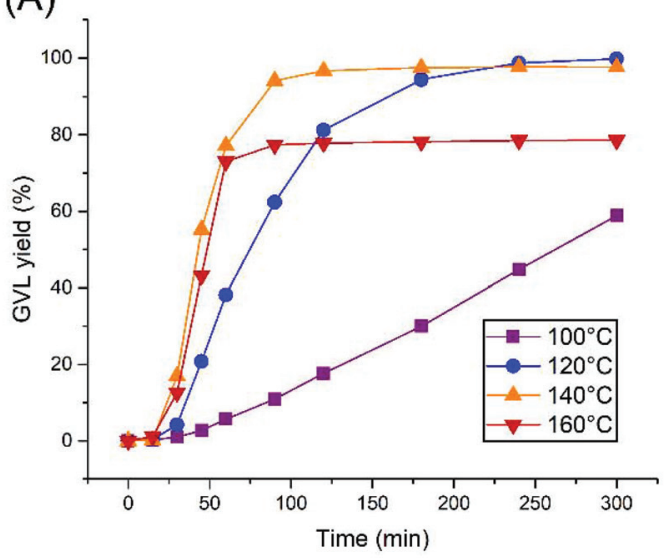

(C)

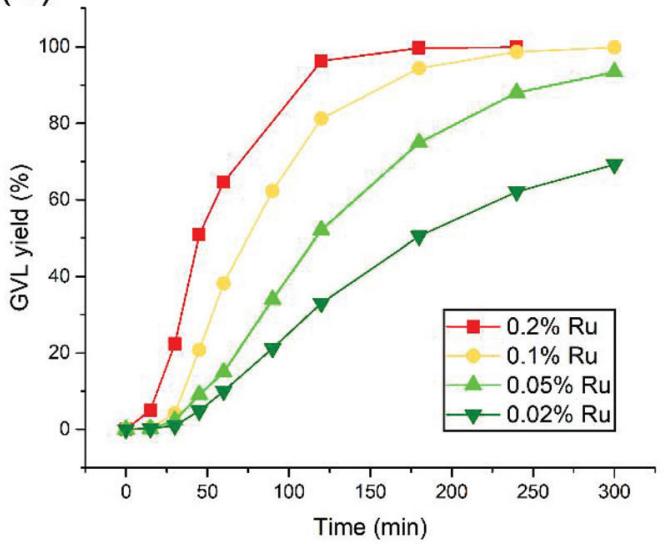

(B)

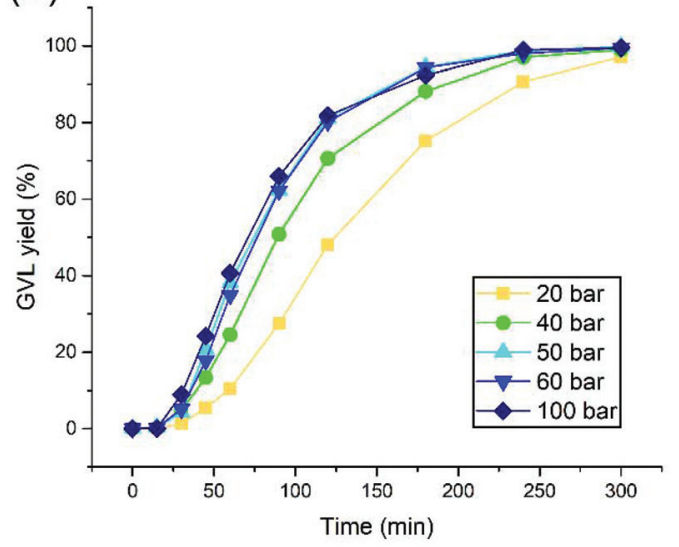

(D)

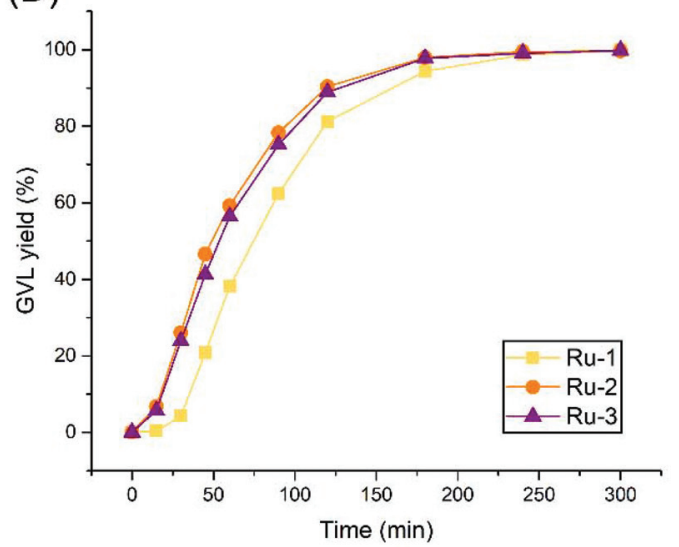

Fig. 1 Parameter optimizations for the solvent-free hydrogenation of LA to GVL, established by the kinetic reaction profiles. The standard conditions are $120^{\circ} \mathrm{C}, 50$ bar $\mathrm{H}_{2}$ (hot pressure), 0.1 mol\% Ru-1, unless indicated otherwise. The investigated parameters concern (A) reaction temperature; (B) $\mathrm{H}_{2}$ pressure; (C) catalyst loading; (D) catalyst precursor using $0.1 \% \mathrm{Ru}$ atoms.

Finally, to retrospectively assess our choice to use Ru-1 in this study, we applied the optimized conditions using Ru-2 and Ru-3 (Fig. 1D). These two dimeric species were observed to become much more readily active within the first 30 minutes than Ru-1, although keeping in mind that the slower LA conversion within the first 15 minutes most likely corresponds to the heating ramp of the autoclave. Consequently, the reactions catalyzed by Ru-2 and Ru-3 finish 1 hour earlier compared to Ru-1. However, their maximal TOF's render 711 and $678 \mathrm{~h}^{-1}$, respectively, which is in the same order of magnitude compared to the rate observed for Ru-1. Hence, despite their immediate activation, Ru-2 and Ru-3 do not bear significant advantages over Ru-1 in terms of catalytic activity.

The sigmoidal curves observed for Ru-1 throughout these kinetic studies could be rationalized further by build-up of water over the course of the hydrogenation reaction, which is

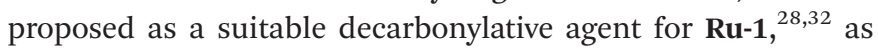
well as for $\mathbf{F e}-\mathbf{1}^{33}$ Since numerous examples of such catalyst decarbonylations are described using various bases ${ }^{34}$ or trimethylamine oxide, ${ }^{35}$ a similar mechanism can be realized with water acting as an Arrhenius base (ESI, Scheme S1.2†). A
Karl-Fischer titration of the used LA stock revealed a water concentration of 2022 ppm, which equals 0.002 equivalent with respect to LA. It is plausible this initial presence of water indeed activates a part of the present Ru-1 into Ru-4 upon heating. As such, the LA hydrogenation can be enabled, so that the $\mathrm{H}_{2} \mathrm{O}$ concentration accumulates further, and pushes the Ru-1 decarbonylation to completion, as observed in the kinetic curves.

\subsection{Catalyst recycling studies and the effect of water}

Attempts to recycle the catalyst were conducted in a similar manner as earlier reported by Fábos et $a l^{22}$ Careful vacuum distillation of the reaction mixture yields water $\left(50{ }^{\circ} \mathrm{C}\right.$, 40 mbar) first, and then GVL $\left(90^{\circ} \mathrm{C}, 1\right.$ mbar $)$. The catalyst remains in the residue as an orange solid along with a trace amount of GVL or unreacted LA, and is dissolved in fresh LA for recycling. Unfortunately, after the successful run with fresh catalyst, the conversion of the first and second recycles decreased to $85 \%$ and $36 \%$, respectively. This result was surprising, since Fábos et al. reported three successful recycles of Ru-2 without loss of activity. ${ }^{22}$ Therefore, several possibilities 
were considered, that may have caused catalyst deactivation in our hands.

Firstly, we focused on ascribing this problem to either our hydrogenation procedure, or to the catalyst recovery. To exclude the possibility of catalyst deactivation by exposure to oxygen upon opening the autoclave after the regular reaction time of 5 hours, a 32 hours long experiment with $0.005 \%$ Ru-1 at $120{ }^{\circ} \mathrm{C}$ and 50 bar $\mathrm{H}_{2}$ was devised, in order to either confirm or dismiss an increased activity compared to the cumulative TONs of the recycling experiments. This reaction rendered a total TON of 9140, upon which a plateau was observed after 10 hours, confirming catalyst deactivation (ESI, Fig. S2.1†). This result suggests a certain aspect in the present hydrogenation procedure to be the critical factor in causing catalyst deactivation.

In an attempt to elucidate the catalyst deactivation on molecular level, the catalysts used in one run were isolated in vacuo. ${ }^{13} \mathrm{C}$ NMR analysis of the residual catalyst from the $\mathrm{H}_{2}$-hydrogenation reveals a distinct peak pattern for the three different carbon sets in the cyclopentadienone ring and the metalbound carbonyls, which do not match with the signals found for Ru-1, Ru-2, and Ru-3, or with the starting materials to synthesize these catalyst precursors (Fig. 2). The disappearance of the signal at $174 \mathrm{ppm}$ and appearance of a signal at $108 \mathrm{ppm}$ may be an indicator for a change in the architecture of the ligand (e.g. deoxygenation), rendering the deactivated material to be a unique species. We also isolated the catalyst used after the FA-mediated transfer hydrogenation for analysis, however, in this case the successful reformation of Ru-2 was observed.

Considering these results, some plausible explanations for the catalyst deactivation appear to rely on differences between this work and the catalytic system of Fábos et al. ${ }^{22}$ Since our recycling studies were performed at $120^{\circ} \mathrm{C}$ instead of $100{ }^{\circ} \mathrm{C}$, while observing catalyst deactivation within 3 hours at $140{ }^{\circ} \mathrm{C}$

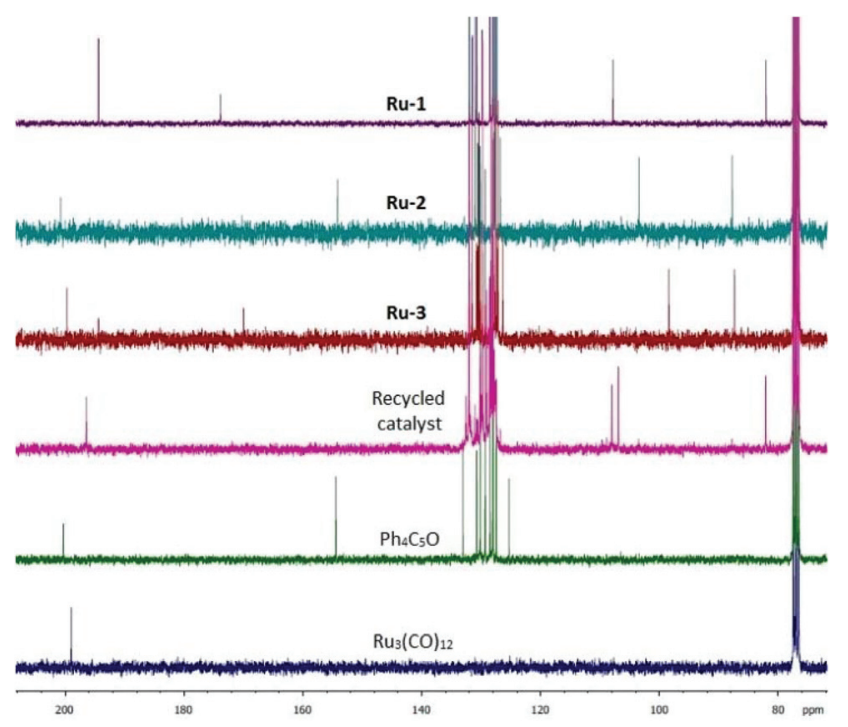

Fig. $2{ }^{13} \mathrm{C}$ NMR spectra of the catalyst precursors, and the recycled material derived from Ru-1.

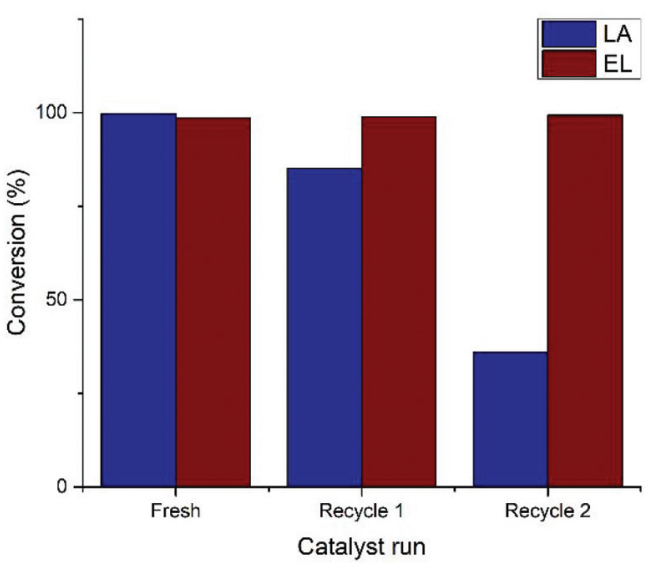

Fig. 3 Recycling studies of Ru-1 in the hydrogenation of LA and EL. Conditions: $0.1 \%$ Ru- 1 in LA (neat) under 50 bar $\mathrm{H}_{2}$ pressure at $120^{\circ} \mathrm{C}$.

(Fig. 1A), eventual deactivation at lower temperatures remains a possibility after a longer time. On the other hand, in our work $\mathrm{H}_{2}$ was used as reductant instead of FA. While association of $\mathrm{H}_{2}$ to any of the Shvo catalyst precursors leads to the sensitive $\mathbf{R u - 4}$, association of FA to $\mathbf{R u - 2}$ could potentially yield a stable organometallic adduct in situ.

However, a vital clue was found in the work of Pasini et al., who applied the Shvo catalyst in the hydrogenation of HMF at $90{ }^{\circ} \mathrm{C}^{36}$ Herein, recycling studies of $\mathbf{R u}-\mathbf{2}$ from both toluene as well as a biphasic water/toluene medium, and the introduction of water was evidenced to be destructive for the catalyst. In light of this information, we sought to eliminate water from LA hydrogenation in this work, and replaced LA by ethyl levulinate (EL), which co-produces ethanol instead of water. Strikingly, the Shvo catalyst applied in this reaction could be reused without losing activity after two recycles (Fig. 3). Moreover, the kinetic curve of EL was found to be practically identical to that of LA hydrogenation under the optimal conditions (ESI, Fig. S2.2†). The use of EL instead of LA is therefore a more preferable substrate for the synthesis of GVL by $\mathrm{H}_{2}$-mediated hydrogenation using Shvo-type catalysts.

Evaluating the role of water in catalyst deactivation further, this concept does not readily apply to the work of Fábos et al. ${ }^{22}$ However, their three successful catalyst recycles could rely on experimental differences. We believe the use of FA as hydrogen donor is the most likely cause, and possibly manifests via more stabilization of the catalytic species and/or dilution of all components in the reaction mixture.

\subsection{Kinetic and thermodynamic comparison of hydrogen donors by DFT calculations}

Reflecting on the kinetic reaction profiles at different temperatures in this work, a significantly lower activity is observed for the $\mathrm{H}_{2}$-hydrogenation of LA at $100{ }^{\circ} \mathrm{C}$ in this work (Fig. 1A), than for the FA-mediated hydrogenation at $100{ }^{\circ} \mathrm{C}$ (with Ru-2), as described by Fábos et al. ${ }^{22}$ The maximal TOF's for these are $144 \mathrm{~h}^{-1}$ and approximately $400 \mathrm{~h}^{-1}$, respectively. However, upon increasing the temperature of the $\mathrm{H}_{2}$-hydrogenation this 
difference is annulled. In addition, the hydrogenation of LA with $\mathrm{H}_{2}$ in this work proceeds relatively fast, compared to the transfer hydrogenation with IPA (in toluene at $80^{\circ} \mathrm{C}$ ), which we reported earlier. ${ }^{27}$

For a fair comparison, we repeated the solvent-free transfer hydrogenations of LA to GVL catalyzed by $0.1 \%$ Ru-1 using 2.5 equivalents of FA and IPA, respectively, at $100{ }^{\circ} \mathrm{C}$ and $120{ }^{\circ} \mathrm{C}$ (Fig. 4). To allow temperatures above the boiling point of IPA, the reactions were performed in an autoclave under 2.5 bar of $\mathrm{N}_{2}$ atmosphere. Since the reaction with FA releases stoichiometric amounts of $\mathrm{CO}_{2}$, a pressurized reaction was not considered feasible and only $100{ }^{\circ} \mathrm{C}$ was applied. Moreover, no activation of Ru-1 with FA as hydrogen donor was observed, hence Ru-2 was used instead. At $100{ }^{\circ} \mathrm{C}$ reaction rates were observed in the order FA $>\mathrm{H}_{2}>$ IPA, rendering TOF's of 498, 144 , and $81 \mathrm{~h}^{-1}$ in the linear regions, respectively. Upon applying an increased temperature of $120{ }^{\circ} \mathrm{C}$ to the reactions with $\mathrm{H}_{2}$ and IPA the reaction rates increased to 598 and $257 \mathrm{~h}^{-1}$, respectively.

In order to elucidate these experimental outcomes, DFT calculations were performed. Herein, the goal is to compare the energetic hydrogenation pathways, facilitated by $\mathrm{H}_{2}$, IPA, and FA, and to correlate the results with the experimental findings. The computational structures were optimized using the hybrid B3LYP function, ${ }^{37}$ and the LANL2DZ core potential ${ }^{38}$ was applied on all atoms. Unlike some earlier reports, ${ }^{39}$ in this work the Shvo catalyst was computed without any structural simplification. Since Hollmann et al. ${ }^{40}$ identified two energetic minima regarding the conformation of the four phenyl rings (i.e. mirror and propeller; Fig. 5), we have taken both conformations into account for these calculations. The energetic difference between these two conformations varies from 0.0 to $2.1 \mathrm{kcal} \mathrm{mol}^{-1}$ throughout our calculated structures, as a result of steric hindrance. However, conformational interchange is considered possible at any stage of the catalytic mechanism.

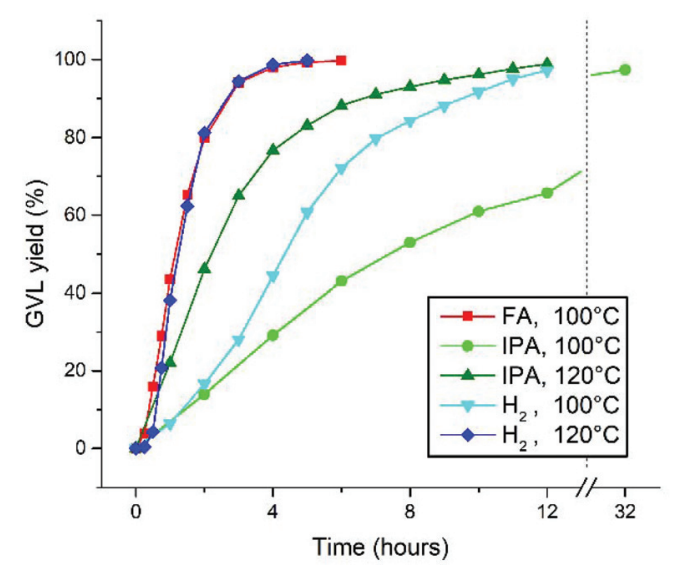

Fig. 4 Catalytic conversion of LA to GVL using different $\mathrm{H}$-donors and temperatures. Conditions: $0.1 \% \mathrm{Ru}-1$ in $\mathrm{LA}$ (neat) under 50 bar $\mathrm{H}_{2} ; 0.1 \%$ Ru-1 in a mixture of 1 equiv. LA in 2.5 equiv. IPA; $0.1 \%$ Ru-2 in a mixture of 1 equiv. LA in 2.5 equiv. FA.

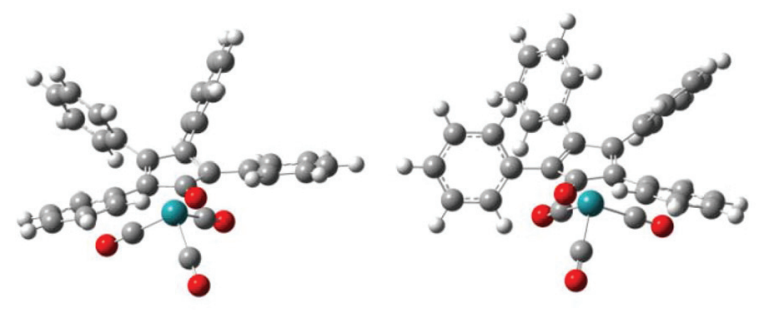

Fig. 5 The two different conformations of the phenyl substituents of Ru-1. Left structure is 'mirror'; right structure is 'propeller'.

For the hydrogen transfers mediated by the Shvo catalyst, the mechanisms of Assary et $a .^{41}$ and Casey et $a{ }^{42}{ }^{42}$ concerning FA and alcohols, respectively, were assumed. The mechanism for the splitting of $\mathrm{H}_{2}$ is also adapted from Casey et al. These structural mechanisms are shown in Fig. 6-8 (vide infra), and always feature a concerted hydrogen transfer, which has been evidenced unanimously before. ${ }^{31,42,43}$

In closer detail, the generic catalytic cycle can be accessed by the formation of either $\mathbf{R u - 4 , ~ R u - 5 , ~ o r ~ b o t h , ~ d e p e n d i n g ~ o n ~}$ the used catalyst precursor. In Scheme 3, the catalytic cycle starts with Ru-5 (I). From here, a hydrogen donor associates to the catalyst (II), and the transition state is crossed via a concerted heterolytic hydrogen transfer (in case of FA and IPA as hydrogen donors) (TS1). As such, a protonic and a hydridic moiety are generated on the catalyst, while the residual part of the hydrogen donor (if present) has become carbonylic (III), and is then dissociated to form the active $18 \mathrm{e}^{-}$species $\mathbf{R u}-\mathbf{4}$ (IV). Subsequently, LA associates onto Ru-4 in an outer-sphere fashion (V). Next, another transition state is crossed (TS2), corresponding to the concerted transfer of the proton and hydride of Ru-4 to the ketone functionality of LA. Hence, the catalyst is reverted into a $16 \mathrm{e}^{-}$species, while LA is converted into 4-hydroxyvaleric acid (4-HVA) (VI). The catalytic cycle is closed by the dissociation of 4-HVA (VII), however, 4-HVA cyclizes spontaneously into GVL via the extrusion of water (VIII).

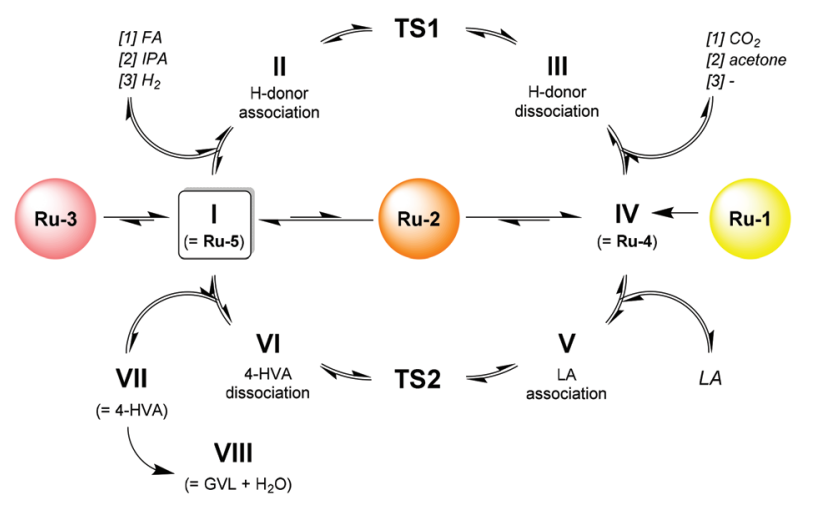

Scheme 3 Generic catalytic cycle for the Shvo-catalyzed hydrogenation of LA to GVL. 


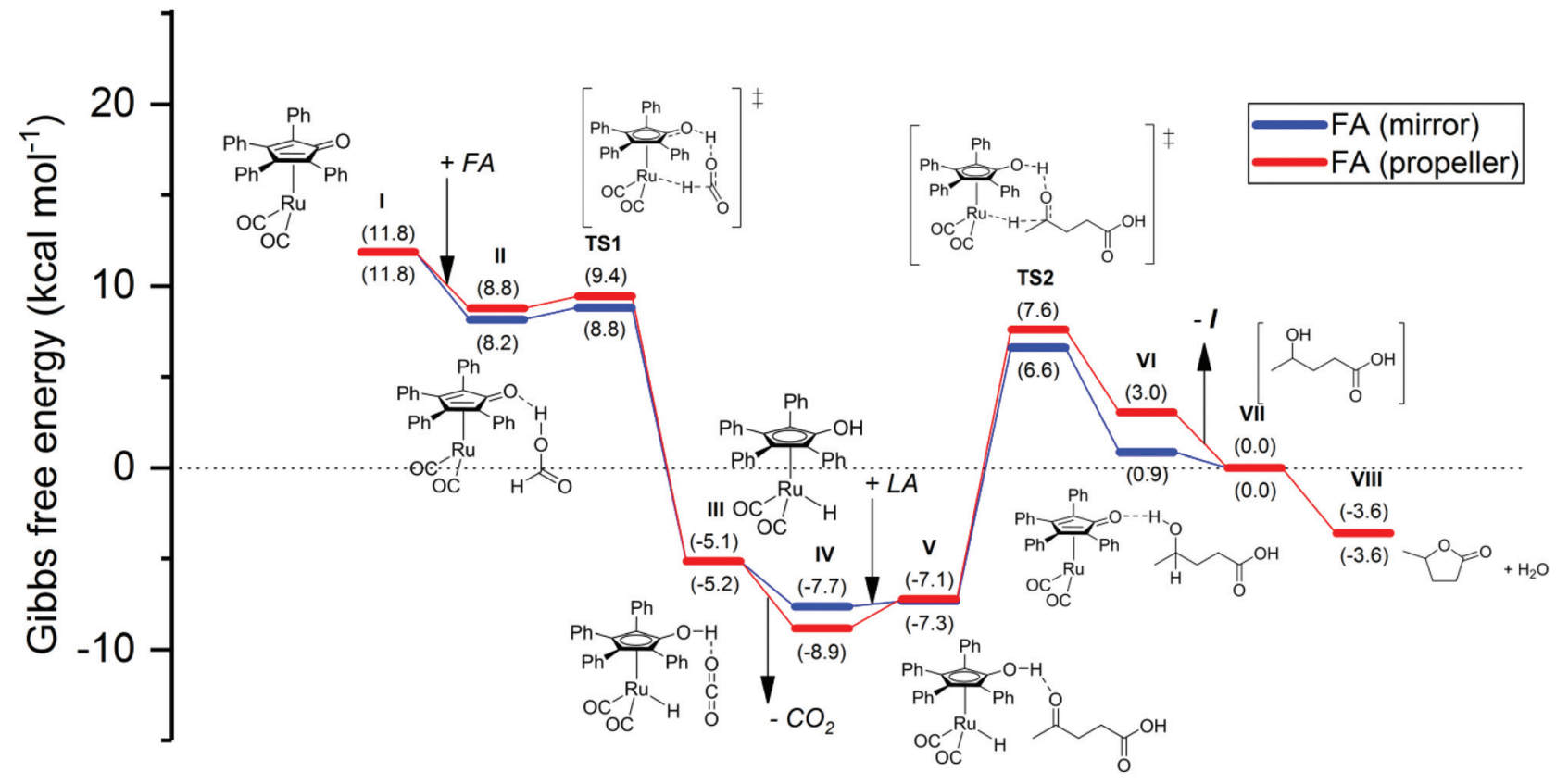

\section{Reaction coordinate}

Fig. 6 Energetic reaction profile for the regeneration of the active Shvo catalyst species using FA, followed by the Shvo-catalyzed hydrogenation of LA to GVL. The Gibbs free energy is normalized as such, that stage VII equals $0.0 \mathrm{kcal} \mathrm{mol}^{-1}$. A summary of the computational outputs is provided in the ESI. $\dagger$

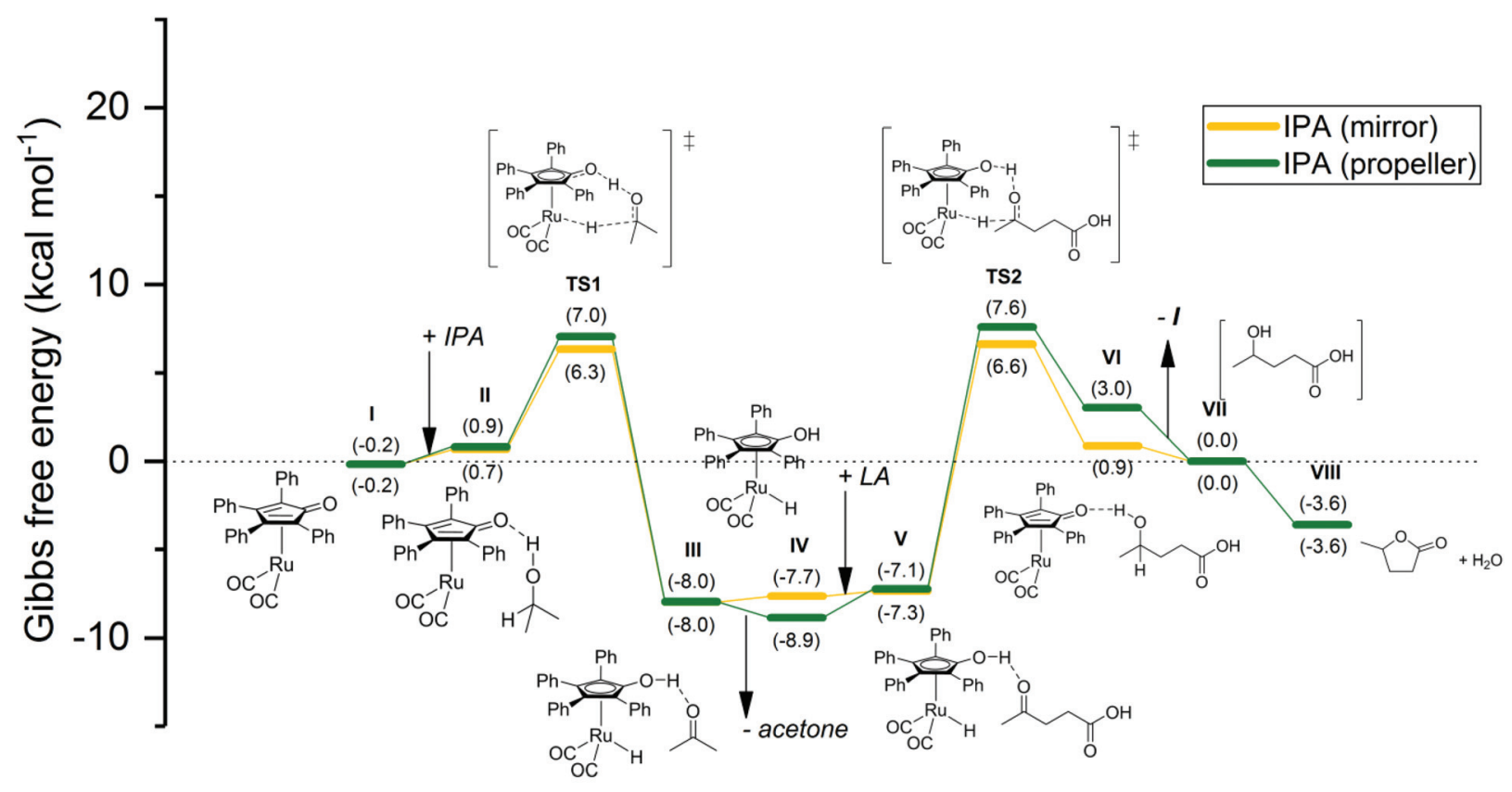

Reaction coordinate

Fig. 7 Energetic reaction profile for the regeneration of the active Shvo catalyst species using IPA, followed by the Shvo-catalyzed hydrogenation of LA to GVL. The Gibbs free energy is normalized as such, that stage VII equals $0.0 \mathrm{kcal} \mathrm{mol}^{-1}$. A summary of the computational outputs is provided in the ESI.† 


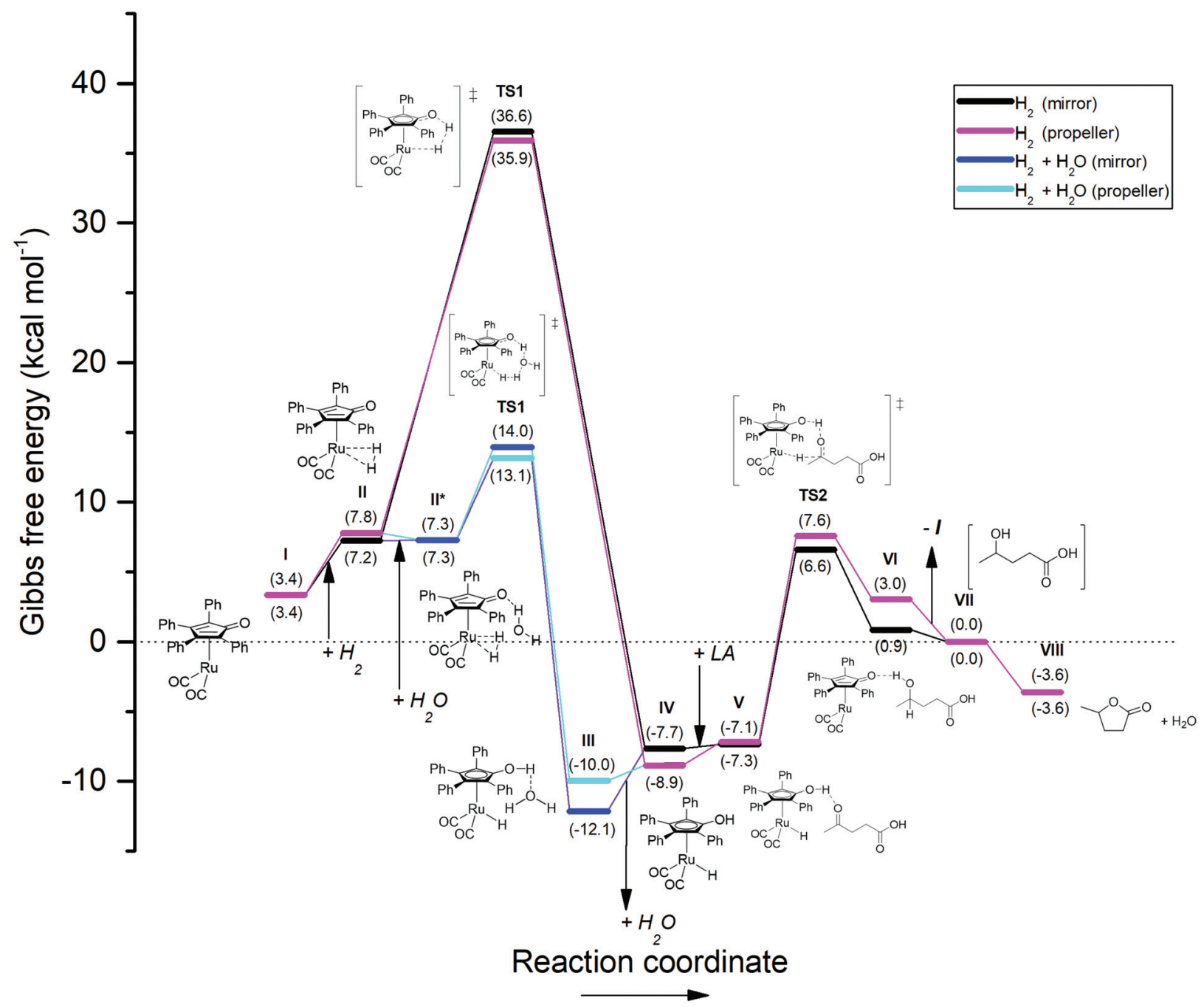

Fig. 8 Energetic reaction profile for the regeneration of the active Shvo catalyst species using $\mathrm{H}_{2}$, followed by the Shvo-catalyzed hydrogenation of LA to GVL. The by-pass reaction pathway colored in blue depicts the energetic profile for the splitting of $\mathrm{H}_{2}$ co-catalyzed by a water molecule. The Gibbs free energy is normalized as such, that stage VII equals $0.0 \mathrm{kcal} \mathrm{mol}^{-1}$. A summary of the computational outputs is provided in the ESI. $\dagger$

The reaction with FA (Fig. 6) was firstly remodeled, since only a simplified version of the Shvo catalyst was reported by Assary et al., who substituted its phenyl groups with hydrogens. ${ }^{41}$ It should be noted that, although our results are for the larger part qualitatively the same, the presence of the phenyl groups has a significant influence on the Gibbs free energy differentials, that are steric as well as electronic in nature.

Our calculations reveal an energetically favorable association of FA to Ru-5 (step I-II), followed by a practically nonexistent transition barrier $\left(\Delta G_{\mathrm{TS} 1}=0.0-1.2 \mathrm{kcal} \mathrm{mol}^{-1}\right)$ for the hydrogen transfer (TS1). The subsequent formation and dissociation of $\mathrm{CO}_{2}$ (step TS1 - IV) renders a combined exothermic value of $16.5-18.3 \mathrm{kcal} \mathrm{mol}^{-1}$. In the second part (step IVVIII), which is identical for all three reactions in terms of $\Delta G$, LA association to Ru-4 appears only slightly endothermic $\left(\Delta G_{\mathrm{TS} 2}=0.4-1.8 \mathrm{kcal} \mathrm{mol}^{-1}\right)$, while the hydrogen transfer to LA features a transition barrier of 13.7-14.9 $\mathrm{kcal} \mathrm{mol}^{-1}$ (TS2).
Ultimately, the dissociation of 4-HVA and its cyclization (step TS2 - VIII) are calculated to be an all-exothermic pathway of 9.2-10.2 $\mathrm{kcal} \mathrm{mol}^{-1}$ to yield GVL. This result suggests that activation of Ru-5 by FA (step I to IV) is practically a spontaneous process, and therefore the hydrogen transfer to LA (TS2) is the rate-determining step. Moreover, the pathway from I to IV is unlikely to revert in case of FA, because the gaseous $\mathrm{CO}_{2}$ byproduct readily evaporates from the reaction mixture. However, despite such favorable conditions, a minimal temperature of $80{ }^{\circ} \mathrm{C}$ is still required, because at lower temperatures $\mathbf{R u}-\mathbf{4}$ tends to dimerize into inactive $\mathbf{R u}-\mathbf{2}$.

The energetic reaction profile for the transfer hydrogenation using IPA was also calculated as a reference to our experimental work reported earlier (Fig. 7). ${ }^{27}$ Herein, the regeneration of Ru-4 features a slightly endothermic association of IPA to Ru-5 (step I-II), rendering $0.9-1.1 \mathrm{kcal} \mathrm{mol}^{-1}$. This is followed by a transition barrier of 5.4-6.3 $\mathrm{kcal} \mathrm{mol}^{-1}$ for the hydrogen transfer (TS1). The subsequent extrusion of acetone 
renders an exothermic 14.4-15.0 kcal $\mathrm{mol}^{-1}$, which is quantitatively comparable to the energetic barrier of TS2. As such, a rather symmetric energetic profile concerning step I-VII is observed. This correlates with the Meerwein-Ponndorf-Verley equilibrium, however, the reaction is ultimately dragged to completion by the exothermic cyclization of 4-HVA to GVL (step VII-VIII).

Finally, to probe our present work into this thermodynamic context, the pathway in which $\mathrm{H}_{2}$ is heterolytically split by $\mathbf{R u}-\mathbf{5}$ directly was first calculated (Fig. 8, black and purple plots). As such, the catalyst regeneration is initiated by an endothermic association of $\mathrm{H}_{2}$ onto the ruthenium atom of $\mathbf{R u}-\mathbf{5}$, rendering 3.8-4.4 kcal mol${ }^{-1}$ (I-II). Then, via transfer of one hydrogen atom to the cyclopentadienone ligand, the transition state for hydrogen splitting is engaged (TS1, black and purple plots), which leads directly to the formation of Ru-4 without the formation of by-products (IV). This process consumes a remarkably high 28.1-29.4 $\mathrm{kcal} \mathrm{mol}^{-1}$ for TS1, but releases a seemingly irreversible $43.6-45.5 \mathrm{kcal} \mathrm{mol}^{-1}$ for step TS1 - IV. Hence, the rate-determining step in this scenario appears to be the splitting of $\mathrm{H}_{2}$ instead of hydrogen transfer to LA, unlike the cases for the reactions with FA and IPA.

Although certain values of about $29 \mathrm{kcal} \mathrm{mol}^{-1}$ were reported to be viable for $\mathrm{H}_{2}$ splitting by structurally related iron Knölker-type catalysts, ${ }^{43}$ this computational outcome does not correlate with our experimental findings. Therefore we also considered an alternative reaction pathway featuring a 'waterrelay' mechanism (Fig. 8, blue plot), which is evidenced via deuterium labelling studies by Casey et al. ${ }^{42 a}$ According to this mechanism, after $\mathrm{H}_{2}$ association to Ru-5 (II), a water molecule associates onto the cyclopentadienone ligand (II*). A transition barrier of only 5.8-6.7 $\mathrm{kcal} \mathrm{mol}^{-1}$ is then observed for the water-mediated hydrogen transfer, in which one hydrogen atom from $\mathrm{H}_{2}$ is donated to the oxygen atom of the water, while the water molecule passes one of its own hydrogens to the cyclopentadienone ligand in a concerted way (TS1). The following completion of the hydrogen transfer and dissociation of water (step TS1 - IV) yield Ru-4 as well. Since the transition barrier for water-catalyzed $\mathrm{H}_{2}$ splitting is notably lower compared to that of the 'dry' mechanism, and the hydrogenation of LA to GVL co-produces water, we regard only the 'water-relay' mechanism as representable for our study. Importantly, the co-catalysis by water causes the energetic barrier of TS1 to become lower than that of TS2, hence turning TS2 into the rate-determining step.

Alternatively, $\mathrm{H}_{2}$ splitting aided by the carboxylic acid functionality of LA is another potential mechanism that could take place in this particular reaction. Although no experimental evidence for $\mathrm{H}_{2}$ splitting by Shvo-type catalysts employing carboxylic acids as co-catalysts is available in literature yet, examples of hydrogen-shuttling induced by phosphoric acids are known, ${ }^{44}$ of which some also involve the related Knölker catalyst. $^{34 b-e, 45}$ Based on the interactions described in these reports and the 'water-relay' mechanism by Casey et al., ${ }^{42 a}$ we considered similar concerted mechanisms, in which classical hybridization of the acidic oxygen atoms of LA was assumed.
After $\mathrm{H}_{2}$ association to $\mathbf{R u}-\mathbf{5}$ (II), LA associates with its acidic proton to the cyclopentadienone ligand. Then, two modes of concerted $\mathrm{H}_{2}$ splitting co-catalyzed by LA were considered: (a) One hydrogen from $\mathrm{H}_{2}$ migrates to the $\mathrm{sp}^{3}$-hybridized oxygen of LA, which simultaneously donates its own acidic proton to the cyclopentadienone ligand, followed by dissociation of levulinic acid forming Ru-4. This mode is nearly identical to the 'water-relay' mechanism in terms of mechanistic atom interactions, as well as the energetic pathway, rendering a transition barrier of 5.4-6.8 kcal mol${ }^{-1}$ (ESI, Fig. S4.1†). Hence, this interaction could possibly co-exist with the 'water-relay' mechanism in the reaction, but providing spectroscopic distinction between these mechanisms is deemed impossible due to proton-scrambling. (b) The other investigated mode concerns a relay mechanism involving both carboxylic oxygen atoms. One hydrogen from $\mathrm{H}_{2}$ migrates to the $\mathrm{sp}^{2}$-hybridized oxygen of LA, which transfers its electron density via the carboxylic carbon to the $\mathrm{sp}^{3}$-hybridized oxygen, and simultaneously donating the acidic proton to the cyclopentadienone ligand as such, which is most resembling to related interactions by phosphoric acids. ${ }^{34 b-e, 44,45}$ This mode of LA association to the Shvo catalyst and $\mathrm{H}_{2}$, as well as the resting state after hydrogen splitting are found more exergonic than the previously described interaction with LA. However, the found transition state for the anticipated concerted hydrogen-transfer mechanism reveals a negative $\Delta G$, and the corresponding molecular vibration is only visible for the splitting of $\mathrm{H}_{2}$, but not for the transfer of the proton from LA to the cyclopentadienone ligand (ESI, Fig. S4.2†). This mismatch suggests that the proposed concerted mechanism in this particular mode may not be existent.

Thus, based on our DFT studies, viable reaction pathways for the Shvo-catalyzed (transfer) hydrogenation of LA to GVL using FA, IPA, $\mathrm{H}_{2}+\mathrm{H}_{2} \mathrm{O}$, and one interaction mode for $\mathrm{H}_{2}+\mathrm{LA}$ as hydrogen donors were calculated. For each of the four hydrogen donor combinations the hydrogen transfer to LA (TS2) is predicted to be the rate-determining step. On the other hand, the thermodynamic gain for the catalyst activation by the hydrogen donor - and therefore for the entire reaction is in the order: FA $>\mathrm{H}_{2}+\mathrm{H}_{2} \mathrm{O}=\mathrm{H}_{2}+\mathrm{LA}>$ IPA. Since the magnitude of $\Delta G$ co-defines the reaction equilibrium as eqn (1), it also controls the reaction rate by establishing the equilibria throughout step I-VIII. Therefore, the order of $\Delta G$ for FA, IPA, $\mathrm{H}_{2}+\mathrm{H}_{2} \mathrm{O}$, and $\mathrm{H}_{2}+$ LA is qualitatively in accordance with the observed reaction rates for the corresponding hydrogen donors at equithermal conditions.

$$
K=\frac{[\mathrm{GVL}]\left[\mathrm{H}_{2} \mathrm{O}\right][\text { byproduct }]}{[\mathrm{LA}][\mathrm{H} \text {-donor }]}=e^{-\frac{\Delta G}{R T}}
$$

\subsection{Life cycle assessment}

With the complete, optimized experimental data, and a rational overview of thermodynamic feasibility for all Shvocatalyzed (transfer) hydrogenations of LA to GVL at hand, it is interesting to identify the most desirable methodology with 
respect to green chemistry practices. A quantitative expression in terms of environmental impact can be derived from a LCA as an accurate indicator or comparative value for such.

LCA is an analytical tool, that is standardized in the ISO 14040 series, $^{46}$ to assess the environmental impact of a product or service. Herein, the combined total of all material inputs and outputs, energy consumption, and other process attributes (e.g. workup procedures, transport, waste management) are preferably included as complete as possible for an accurate assessment. ${ }^{47}$

In recent years, numerous LCAs in the field of chemistry have appeared, with the focus on evidencing the benefit of applying bio-based feedstock, ${ }^{48}$ alternative synthesis routes, ${ }^{49}$ and innovative procedures. ${ }^{50}$ However, many of these novel researches are merely conducted in early-development stages, such as laboratory scale or computational process simulations. Hence, their corresponding LCA's are prospective, with the purpose of, for example, identifying the key aspects towards improvement in upscaling, ${ }^{51}$ or to compare the benefit of choosing a raw material from a selection. ${ }^{48 a, 52}$

In this work, we performed a prospective LCA comprising a comparison of several reaction parameters for the Shvo-catalyzed (transfer) hydrogenation of LA to GVL, in terms of environmental impact. These parameters concern the catalyst precursor, hydrogen donor, temperature, and time of the reaction, aiming for the optimal balance between environmental impact and process metrics. The included reactions are described in section 2.4 (Scheme 4), and the function studied in this LCA is the production and isolation of GVL.

The life cycle inventory (LCI) comprises three different hydrogenation methods, which are [1] transfer hydrogenation using FA and emitting $\mathrm{CO}_{2}$, [2] transfer hydrogenation using IPA and co-producing acetone, and [3] direct hydrogenation using $\mathrm{H}_{2}$ without generating any by-product. Herein, the boundaries of this LCA are chosen to be 'gate-to-gate' for the production and isolation of GVL from LA (Scheme 4). This means that the environmental impact of consumed chemicals, electric energy input, and downstream processing (DSP) are taken into account for this chemical transformation, but not for the synthesis of LA from primary resources. Excluding the environmental impact of LA synthesis can only provide reliable comparisons, if the assessed LA hydrogenations achieve 100\% conversion to GVL with complete isolation. We consider it reasonable to assume this for the present work, given that all the actual LA conversions equal at least 97\%. The choice for this boundary was made, because the only reported LCA on LA production to our knowledge is based on a process model and is too specific with respect to a location or feedstock, ${ }^{47 b}$ and is therefore not representative for this work. Moreover, as GVL provides a very wide versatility in further applications and products, its 'end-of-life' scenario is regarded as yet undefined in this work. The applied Shvo catalyst precursors were modelled as 'cradle-to-gate' (vide infra), to demonstrate the environmental impact for their synthesis and use in this reaction. ${ }^{4}$

The present LCA is modelled in accordance with the experimental execution described in sections 2.2, 2.3, and 2.4. All hydrogenation reactions were performed on laboratory scale, rendering 20-43 g of GVL product. However, to apply a uniform comparison on representative scale, the functional unit (FU) was chosen as $10 \mathrm{~g}$ of GVL, being in accordance with the product category rules (PCR) of the environmental product declaration (EPD). ${ }^{53}$

As shown in Scheme 4, the procedure for converting LA to GVL is initiated by creating an inert atmosphere for the reaction by purging with nitrogen (and optionally $\mathrm{H}_{2}$, in case of direct hydrogenation). The purged gas is released from the system, thus regarded as waste. In the next step, the (transfer) hydrogenation reaction takes place, for which any of the Shvotype catalyst precursors, any of the three different hydrogen donors, and electric energy are the input. The environmental impact of LA is not taken into account here, since this LCA is a 'gate-to-gate' assessment. Depending on the scenario, residual nitrogen or $\mathrm{H}_{2}$, or $\mathrm{CO}_{2}$ by-product are considered as waste. The GVL product is isolated via the DSP steps, which consume electric energy for heating and cooling water circulation. First, a mild vacuum distillation is applied to remove water, and any residual liquid hydrogen donor (i.e. FA, IPA), and acetone byproduct if present. In the harsh vacuum distillation, pure GVL is distilled from the catalyst. The spent catalyst is discarded in the main scenario, however, catalyst recovery from the distillation residue and recycling is considered in the sensitivity analysis (vide infra).

For the assessment of $\mathbf{R u - 1}, \mathbf{R u}-\mathbf{2}$, and $\mathbf{R u - 3}$, a plausible retrosynthesis was devised on the basis of standard laboratory scale reports found in literature (Scheme 4). ${ }^{54-62}$ Firstly, these Shvo-type catalyst precursors are conventionally synthesized from tetraphenyl-cyclopentadienone and triruthenium dodecacarbonyl, as shown in Scheme 2. Although various procedures for synthesis and purification with different isolated yields exist in literature, ${ }^{22,29,57,64,65}$ those acquired from the present work are adopted as the base case in this LCA. Furthermore, the ligand is produced via the double aldol condensation of benzil and diphenyl ketone, ${ }^{57}$ which are ultimately derived from benzaldehyde and benzyl chloride, respectively. The triruthenium dodecacarbonyl is ultimately produced from metallic ruthenium, ${ }^{5,56}$ which is a by-product from platinum ore mining, purification, and refining processes. ${ }^{56}$

The total procedure for the (transfer) hydrogenation reactions, product isolation, and the catalyst synthesis routes were modelled in Simapro V8 (PRé consultants, NL). The environmental impacts were calculated using the IMPACT 2002+ V2.14 method, and the results are generally expressed as damage categories. ${ }^{66}$ However, mid-point categories were used for the life cycle impact assessment interpretations. The climate change impact was calculated with the IPCC GWP 100a mid-point method, in accordance with the updated method from the Intergovernmental Panel on Climate Change (IPCC). ${ }^{67}$

The potential environmental impacts of the five different hydrogenation scenarios, were investigated on four different end-point categories, and scaled with respect to the functional unit: 
[1], [2], [3] Synthesis of GVL from LA (Gate-to-Gate)

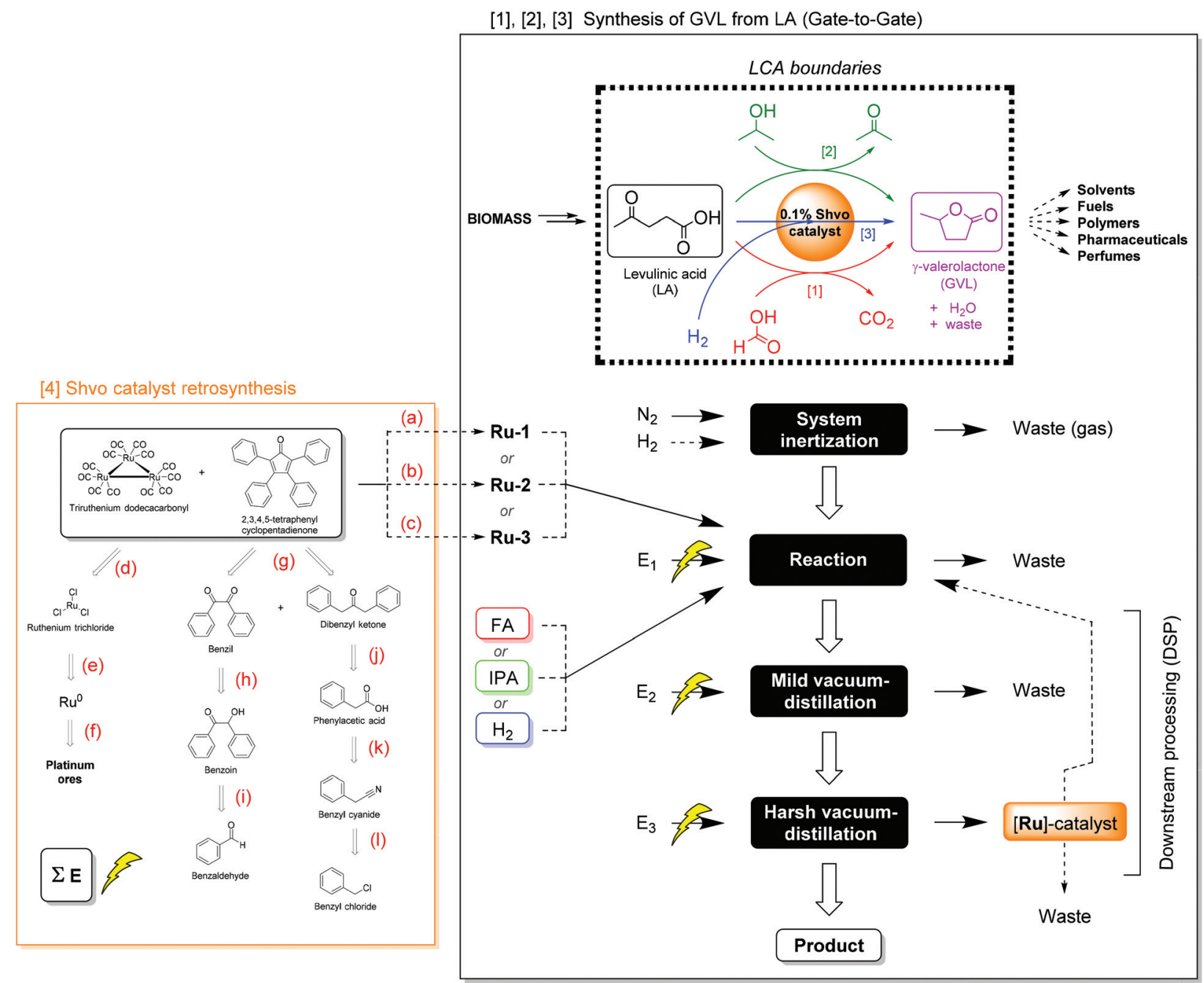

Scheme 4 The studied boundaries and process flow-sheet for the production of GVL from LA on laboratory scale: comparative gate-to-gate assessment including [1] the transfer hydrogenation of the substrate using FA as reductant, [2] the transfer hydrogenation of the substrate using IPA as reductant, [3] the hydrogenation of the substrate using $\mathrm{H}_{2}$, and [4] the syntheses of the Shvo catalyst precursors. Reaction conditions: (a) Metalation (in toluene, $\mathrm{N}_{2}, 110{ }^{\circ} \mathrm{C}, 24 \mathrm{~h}, 98 \%$ ); (b) metalation (in $\mathrm{MeOH}, \mathrm{N}_{2}, 65^{\circ} \mathrm{C}, 24 \mathrm{~h}, 51 \%$ ); (c) metalation (in heptane, $\mathrm{N}_{2}, 100{ }^{\circ} \mathrm{C}, 48 \mathrm{~h}, 58 \%$ ); (d) carbonylation (ethoxyethanol, $\left.\mathrm{CO}, \mathrm{KOH}, 75-135{ }^{\circ} \mathrm{C}, 145 \mathrm{~min}, 96 \%\right) ;{ }^{54}$ (e) chlorination (neat, $\mathrm{Cl}_{2}, 360-390{ }^{\circ} \mathrm{C}, 8 \mathrm{~h}, 100 \%$ ) $;^{55}$ (f) mining/purification/ refining; ${ }^{56}\left(\mathrm{~g}\right.$ ) aldol condensation (in $\mathrm{EtOH}$, Microwave, $70{ }^{\circ} \mathrm{C}, 30 \mathrm{~min}, 78 \%$ ); ${ }^{57}$ (h) oxidation (in $\left.\mathrm{H}_{2} \mathrm{O} / \mathrm{AcOH}_{1} \mathrm{NH}_{4} \mathrm{NO}_{3}, 1 \% \mathrm{Cu}^{\prime \prime}\right) \mathrm{OAc}, 100{ }^{\circ} \mathrm{C}, 2.5 \mathrm{~h}$, $94 \%$ ); ${ }^{58}$ (i) Benzoin condensation (in DMSO, Ar, NaCN, Ultrasound, $25^{\circ} \mathrm{C}, 10 \mathrm{~min}, 98 \%$ ); ${ }^{59}$ (j) Dakin-West reaction (neat, $\mathrm{N}_{2}, \mathrm{Ac}_{2} \mathrm{O}, \mathrm{Et}_{3} \mathrm{~N}, 25^{\circ} \mathrm{C}, 48 \mathrm{~h}$, $69 \%$ ); ${ }^{60}$ (k) hydrolysis (in $\mathrm{H}_{2} \mathrm{O} / \mathrm{H}_{2} \mathrm{SO}_{4}, 100{ }^{\circ} \mathrm{C}, 3 \mathrm{~h}, 78 \%$ ); ${ }^{61}$ (l) Kolbe nitrile synthesis (in $\mathrm{H}_{2} \mathrm{O}, \mathrm{NaCN}, 80{ }^{\circ} \mathrm{C}, 4 \mathrm{~h}, 85 \%$ ). ${ }^{62}$ Reactions a-c are conducted in this work, reactions $\mathrm{d}-\mathrm{l}$ are adapted from literature procedures. Additional chemicals (i.e. ethoxyethanol for reaction d, copper sulfate for reaction $\mathrm{h}$, and triethylamine for reaction j), required in these syntheses, of which the impact could not be derived from the database, were assessed on the basis of literature procedures as well. ${ }^{63}$ Electricity consumptions are denoted as "E" (see ESI Table S5.1† for details). Dashed arrows indicate an optional reaction- or DSP-pathway.

(1) Damage to human health, expressed in disabilityadjusted life year (DALY). This includes human toxicity, respiratory effects, ionizing radiation, ozone-layer depletion, and photochemical oxidation.

(2) Ecosystem quality, expressed in potentially disappeared fraction of species per $\mathrm{m}^{2}$ per year $\left(\mathrm{PDF} \mathrm{m}^{-2}\right.$ year $\left.^{-1}\right)$. Herein, aspects for both aquatic and terrestrial ecotoxicity (e.g. acidification, eutrophication, land occupation) are taken into account.

(3) Climate change, as a result from greenhouse gas emissions into the environment. The severity of the impact per emission type is scaled to $\mathrm{kg} \mathrm{CO}_{2}$ equivalents, in accordance with the global warming potential (GWP) as conversion factor, provided by the IPCC. ${ }^{67}$

(4) Resources, expressed in MJ, are calculated by the sum of energy derived from non-renewable feedstock and mineral extractions.

For the optimized $\mathrm{H}_{2}$-hydrogenation at $120{ }^{\circ} \mathrm{C}$, the relative contributions of process features to the damage categories are presented in Fig. 9. Remarkably, the largest contributors to nearly the entire environmental impact are the electric energy consumption required for the hydrogenation reaction and the 


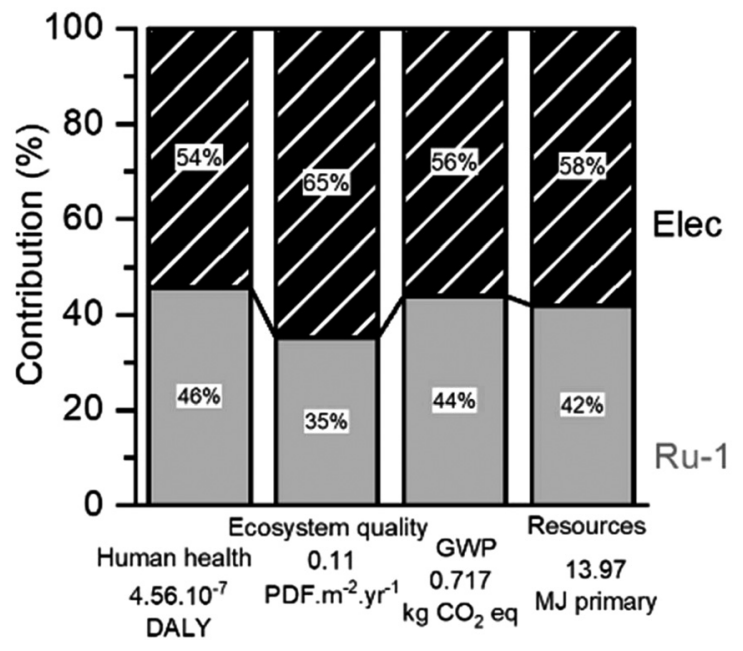

Fig. 9 Magnitude of contribution to four environmental impact categories for the optimized hydrogenation reaction in this work. The total values for each impact category are indicated below the $x$ axis.

catalyst synthesis. This is also found for the other reaction scenarios (ESI S5.1†), but their impact distribution slightly differs. Herein, a trend between the electric energy impact and the reaction duration is clearly visible. However, the lowest electric impact found for the FA-mediated reaction can be rationalized by having the reaction performed in a reflux setup, instead of using an autoclave. Despite the small numerical difference, the impact of $\mathrm{H}_{2}$ consumption appears notably lower than that of FA or IPA. Since the four damage categories always indicate a similar impact distribution, only the GWP was selected for further investigations.

The catalyst synthesis delivers a large part of the impact to this reaction process, while its loading counts only $0.1 \mathrm{~mol} \%$ with respect to LA. Therefore, it is considered worthy to identify the cause of this result, and how to improve it. First, the GWP's of the hydrogenation reactions were modelled as a function of the isolated catalyst yields (Fig. 10). The curves indicate significant reductions of the GWP in all hydrogenation scenarios, however, the relatively highest reductions are seen for the FAand $\mathrm{H}_{2}$-mediated reactions. The yield of Ru-1 in this work is already an excellent 98\%. Contrarily, improving our isolated yield of $51 \%$ for Ru-2 could reduce the GWP of the corresponding FA-mediated hydrogenation reaction up to $27 \%$.

It should be mentioned though, that the GWP of the catalyst is strongly dependent of the applied synthetic procedure as well as the DSP methodology, and isolated yield. Throughout various literature procedures for synthesizing $\mathbf{R u}-1,{ }^{64} \mathbf{R u}-2,{ }^{22,29,57}$ and $\mathbf{R u}-3^{65}$ the electricity consumption originating from the reaction duration and the solvent amount used for column chromatography are found to be the most dominant impact factors (ESI, Fig. S5.2†). The variation in these aspects significantly affects the total GWP of the LA hydrogenation reactions (Fig. 11).

Nevertheless, by considering the isolated yields of Ru-1 and Ru-2 obtained in this work, the magnitude of the environ-

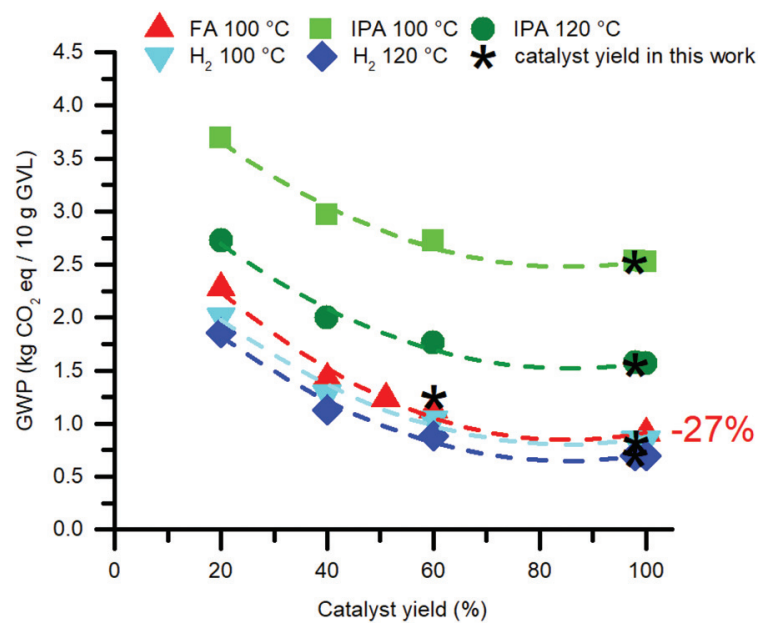

Fig. 10 Reduction of the environmental impact of the catalyst by improving its isolated yield. The catalyst synthesis concerns Ru-1, but for the FA-mediated reaction $\mathbf{R u - 2}$ is modelled.

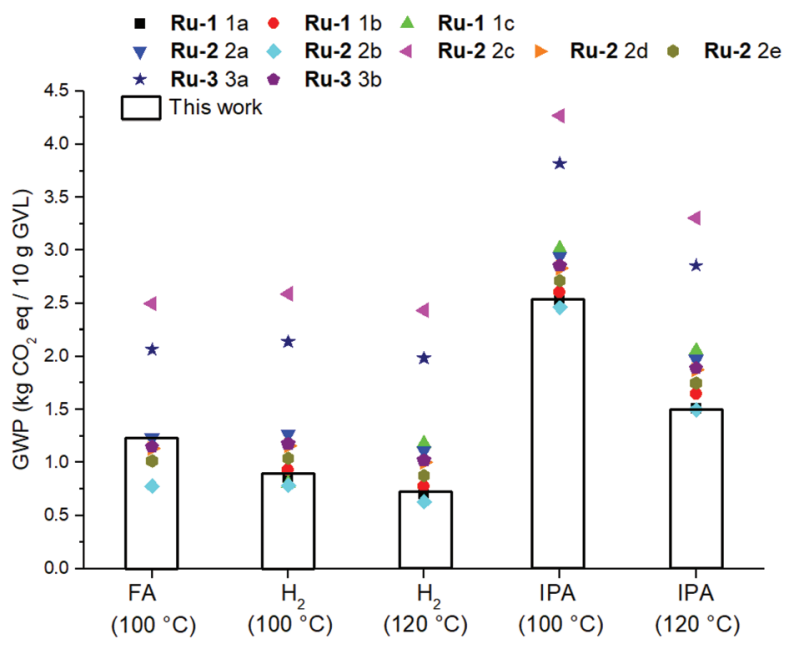

Fig. 11 Sensitivity analysis of the catalyst syntheses in relation to the GWP of the hydrogenation reactions.

mental impact of LA hydrogenation in terms of $\mathrm{H}$-donors is in the order: IPA $>$ FA $>\mathrm{H}_{2}$ (Fig. 11). To eliminate the difference in GWP caused by significantly different isolated yields amongst Ru-1 and Ru-2, but not neglecting the incompatibility of Ru-1 with FA, a combinatorial comparison was devised between the optimal reaction conditions for using each H-donor, and applying each Shvo catalyst precursor with a modelled $98 \%$ isolated yield (ESI S5.3†). Also in this hypothetical circumstance the use of $\mathrm{H}_{2}$ as $\mathrm{H}$-donor shows the lowest GWP.

The environmental impact of the FA-mediated reaction could arguably be reduced in two ways. Since FA is a concomitant by-product from the hydrolysis of HMF to LA (Scheme 1), 1 equivalent of FA can be bio-derived from the same feedstock. As such, the environmental impact for the separation of LA from FA could then be eliminated, however, this separation step is not included within the gate-to-gate boundaries of this 
LCA. Secondly, Fábos et al. have demonstrated the use of only 0.5 equivalents of excess FA to be feasible for $99.9 \%$ conversion, ${ }^{22}$ while 1.5 excessive equivalents were used in this work. Hence, the effects of these two potential eliminations of petrochemical formic acid were assessed in our catalytic system, but even the combination of these effects inflict only a lean $2 \%$ reduction of the GWP (ESI S5.4†).

To furtherly decrease the impact of the catalyst synthesis, the benefit of potential recycling was assessed. Although we concluded that recycling of the Shvo catalyst is incompatible with LA because of deactivation by co-produced water (section 2.3, Fig. 3), it is still interesting to investigate its hypothetical recycling as a model for the EL hydrogenation or even other reactions outside this work. The corresponding calculation can be described by dividing the GWP accounting for the catalyst synthesis by the number of each following hydrogenation cycle, but not for the DSP, as this recurs in each cycle. The obtained plot (ESI, Fig. $5.5 \dagger$ ) reveals a decreasing decline after each recycle, leading to a reduction from $44 \%$ to less than $7 \%$ of the total GWP for the hydrogenation reaction after ten recycles, compared to a reaction without catalyst recycling. Beyond this point an asymptote is reached, whereas 147 recycles are required to draw the catalyst's impact below $1 \%$. We consider a minimum of ten recycles without losing catalytic activity a proper goal to thrive for.

In addition, a further decrease of the environmental impact could be envisioned by immobilizing the catalyst. Supported Shvo-type complexes are known, ${ }^{68}$ and their application would allow facile catalyst separation by filtration. As such, the harsh distillation step in the DSP can be omitted, which reduces the environmental impact by $31 \%$. However, it is important to mention that immobilizing the Shvo catalyst requires extra synthesis steps, which increases the impact of the catalyst synthesis in turn, and catalyst decomposition by sensitivity to water may still occur. In addition, the GVL product is likely to be of lower purity, because in this scenario GVL is collected from the mild distillation residue.

Finally, the duration of the hydrogenation reaction is regarded as the other vital parameter in terms of environmental impact, whereas it is directly proportional to the reaction's electricity consumption. While the applied reaction temperature is one significant factor, also the choice of $\mathrm{H}$-donor plays a dominant role, resulting from the differences in thermodynamic properties amongst the three reaction pathways, as demonstrated by the DFT studies in section 2.4. Based on the kinetic reaction curve in Fig. 1D, a minimum in environmental impact could potentially be realised by mitigating between a shorter reaction time and slightly lower GVL yield. For the LA hydrogenation catalyzed by Ru-1 it is possible to shorten the reaction time for at least 1 hour, while being reacted at $120{ }^{\circ} \mathrm{C}$ under 50 bar $\mathrm{H}_{2}$. However, applying a reaction time under 2 hours goes severely at the cost of the GVL yield, and is therefore deemed not feasible. To illustrate this in a numerical fashion, the GWP was plotted as a function of the reaction time and the isolated yield for $\mathbf{R u - 1}$, which are the two largest contributors to the environmental impact of the base

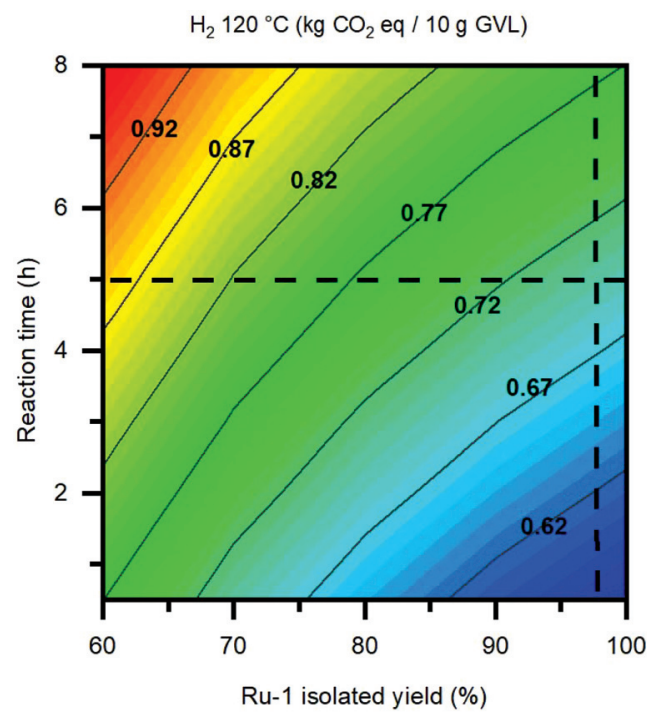

Fig. 12 Expansion of GWP ( $\mathrm{kg} \mathrm{CO}$ equivalents per $10 \mathrm{~g}$ of product) as a function of reaction time and the isolated yield for $\mathrm{Ru}-1$. The optimal reaction established in this work (i.e. $120{ }^{\circ} \mathrm{C}, 50$ bar $\mathrm{H}_{2}$ ) is selected. The crosshair indicates the current isolated yield and reaction time.

case LA hydrogenation in this work (Fig. 12). In this way, an environmentally optimal combination of the reaction parameter values can be pinpointed, in order to achieve the lowest impact possible. In the case of the present reaction, the isolated yield for Ru-1 (98\%) can hardly be improved. However, by shortening the reaction time from 5 hours to 3 hours, an appreciable decrease of $0.5 \mathrm{~kg} \mathrm{CO}$ eq. per $10 \mathrm{~g} \mathrm{GVL}$, corresponding to $7 \%$, can be achieved. LCA representations of this kind can make a useful tool to predict the optimal reaction metrics for developing chemical reactions on laboratory scale into large-scale processes, in the context of green chemistry practices.

\section{Conclusions}

This multi-disciplinary study describes the selective hydrogenation of LA to GVL under solvent-free conditions using the Shvo catalyst. In this specific reaction, the use of hydrogen gas as reducing agent is the novelty, for which the effects of various reaction conditions were thoroughly investigated by means of kinetic studies using the monomeric Shvo-type catalyst Ru-1. The optimal laboratory scale protocol to yield $99.7 \%$ conversion within 5 hours is achieved by heating at $120{ }^{\circ} \mathrm{C}$ under $50 \mathrm{bar}_{2}$, using $0.1 \mathrm{~mol} \%$ [Ru], and this applies to each of the possible Shvo catalyst precursors known.

Attempts to recycle the catalyst from the LA hydrogenation were not successful, since the co-produced water appears to deactivate the catalyst. However, successful catalyst recycling can be achieved by substituting LA for EL, which renders an identical kinetic plot in the same hydrogenation reaction, but co-produces ethanol instead of water.

The comparison of $\mathrm{H}_{2}$ versus other hydrogen donors - FA and IPA - under similar solvent-free conditions result in sig- 
nificantly different reaction rates, in the order of $\mathrm{FA}>\mathrm{H}_{2}>$ IPA. Computational modelling of each reaction using DFT indicate the energetic transition barrier for hydrogen splitting/ transfer generating the active catalytic species, and also the overall exothermic energy loss to be the determining factors in these reaction rates. In addition, the role of water in co-catalyzing $\mathrm{H}_{2}$ splitting via a relay mechanism was considered as a more plausible reaction pathway than direct $\mathrm{H}_{2}$ splitting, based on the magnitude of their energetic transition barriers. As such, the interpretation of the DFT study correlates properly with the experimental observations.

To identify the optimal hydrogen donor from an environmental perspective, the LA hydrogenation procedures featuring the three different hydrogen donors were subjected to a comparative gate-to-gate LCA. Herein, the environmental impacts of the Shvo catalyst precursors are modelled as a cradle-to-gate LCA, mostly based on secondary literature-derived information. The results reveal for all (transfer) hydrogenation reactions, that the total electricity consumption and the catalyst synthesis are the main contributors to the environmental impact with a combined part of $\geq 95 \%$. Sensitivity analysis of these factors shows that a significant variation in the GWP is possible, depending on the reaction duration/temperature/thermodynamics, and synthetic procedure, respectively. Therefore, effectively decreasing the environmental impact could be established by balancing out the reaction time versus the GVL yield, and to apply catalyst recycling (if possible) for at least 10 times.

However, in the optimistic-realistic scenario, where all reactions are assumed to achieve $100 \%$ conversion within their applied optimal reaction conditions, and all catalyst precursor yields are normalized to $98 \%$, the magnitude of environmental impact renders IPA $\gg \mathrm{FA}>\mathrm{H}_{2}$. Hence, the present LCA demonstrates the use of $\mathrm{H}_{2}$ to be the 'greenest' choice, originating from the short reaction time compared to the reaction with IPA, and to the absence of the stoichiometric $\mathrm{CO}_{2}$ by-product compared to the reaction with FA. We expect the environmental benefit of using $\mathrm{H}_{2}$ to be more pronounced in scaledup facilities, which generally display a much higher energy efficiency than laboratory-scale equipment.

With this research, we would also like to emphasize the value of combining different research interests and methodologies in today's chemistry, whereas the interfaces between them may create a pivotal synergy in understanding the chemistry, and therefore how to achieve the greenest and most efficient process.

\section{Conflicts of interest}

The authors state that there are no conflicts to declare.

\section{Acknowledgements}

This work was performed within the framework of the publicprivate knowledge institute of Chemelot InSciTe, who we gratefully acknowledge for their financial support.

\section{References}

1 (a) G. W. Huber, S. Iborra and A. Corma, Chem. Rev., 2006, 106, 4044; (b) A. Corma, S. Iborra and A. Velty, Chem. Rev., 2007, 107, 2411; (c) J. J. Bozell and G. R. Petersen, Green Chem., 2010, 12, 539.

2 (a) R. C. Saxena, D. K. Adhikari and H. B. Goyal, Renewable Sustainable Energy Rev., 2009, 13, 167; (b) P. Mäki-Arvela, B. Holmbom, T. Salmi and D. Y. Murzin, Catal. Rev., 2007, 49, 197; (c) G. Centi, P. Lanzafame and S. Perathoner, Catal. Today, 2011, 167, 14; (d) R. Serrano-Ruiz, A. Luque and A. Sepulveda-Escribano, Chem. Soc. Rev., 2011, 40, 5266.

3 (a) K. H. Kim, M. Tucker and Q. Nguyen, Bioresour. Technol., 2005, 96, 1249-1255; (b) A. Fukuoka and P. L. Dhepe, Angew. Chem., Int. Ed., 2006, 45, 5161-5163; (c) P. Lenihan, A. Orozco, E. O'Neill, M. N. M. Ahmad, D. W. Rooney and G. M. Walker, Chem. Eng. J., 2010, 156, 395-403; (d) D. M. Alonso, J. Q. Bond and A. Dumesic, Green Chem., 2010, 12, 1493-1513.

4 T. Werpy, G. Petersen, A. Aden, J. Bozell, J. Holladay, J. White and A. Manheim, in Top Value Added Chemicals from Biomass: Volume 1 - Results of Screening for Potential Candidates from Sugars and Synthesis Gas, ed. T. Werpy and G. Petersen, U. S. Department of Energy, Washington, DC, 2004.

5 (a) L. Qi, Y. F. Mui, S. W. Lo, M. Y. Lui, G. R. Akien and I. T. Horváth, Chem. Commun., 2012, 48, 5850; (b) L. Yan, Q. Yao and Y. Fu, Green Chem., 2017, 19, 5527.

6 (a) I. T. Horváth, Green Chem., 2008, 10, 1024; (b) J. Q. Bond, D. Wang, D. M. Alonso and J. A. Dumesic, J. Catal., 2011, 281, 290; (c) J. Q. Bond, D. M. Alonso, D. Wang, R. M. West and J. A. Dumesic, Science, 2010, 327, 1110; (d) D. Fegyverneki, L. Orhá, G. Láng and I. T. Horváth, Tetrahedron, 2010, 66, 1078; (e) A. Strádi, M. Molnár, M. Óvári, G. Dibó, F. U. Richter and L. T. Mika, Green Chem., 2013, 15(7), 1857; $(f)$ L. Qi, Y. F. Mui, S. W. Lo, M. Y. Liu, G. R. Akien and I. T. Horváth, ACS Catal., 2015, 4, 1470.

7 V. Fábos, M. Y. Lui, Y. F. Mui, Y. Y. Wong, L. T. Mika, L. Qi, E. Cséfalvay, V. Kovács, T. Szucs and I. T. Horváth, ACS Sustainable Chem. Eng., 2015, 3, 1899.

8 J.-P. Lange, R. Price, P. M. Ayoub, J. Louis, L. Petrus, L. Clarke and H. Gosselink, Angew. Chem., Int. Ed., 2010, 49, 4479.

9 (a) C. W. Lee, R. Urakawa and Y. Kimura, Eur. Polym. J., 1998, 34, 117; (b) M. Chalid, H. J. Heeres and A. A. Broekhuis, J. Appl. Polym. Sci., 2012, 123, 3556; (c) M. Chalid, H. J. Heeres and A. A. Broekhuis, Polym.Plast. Technol. Eng., 2015, 54, 234.

10 J. G. de Vries, Top. Catal., 2014, 57, 1306.

11 Good Scents Company, Parfumery Raw Materials Information Sheet, http://www.thegoodscentscompany. com/data/rw1024031.html.

12 (a) I. T. Horváth, H. Mehdi, V. Fábos, L. Boda and L. T. Mika, Green Chem., 2008, 10, 238-242; (b) C. Y. Y. Wong, A. W-T. Choi, M. Y. Lui, B. Fridrich, 
A. K. Horváth, L. T. Mika and I. T. Horváth, Struct. Chem., 2017, 28, 423.

13 (a) A. K. Ghosh and L. J. Swanson, Org. Chem., 2003, 68, 9823; (b) E. L. Stangeland and T. J. Sammakia, Org. Chem., 2004, 69, 2381; (c) R. Datrika, S. R. Kallam, S. R. Khobare, V. S. Gajare, M. Kommi, H. R. Mohan, V. Siddaiah and T. Pratap, Tetrahedron: Asymmetry, 2016, 27, 603.

14 (a) W. H. R. Wright and R. Palkovits, ChemSusChem, 2012, 5, 1657; (b) U. Omoruyi, S. Page, J. Hallett and P. W. Miller, ChemSusChem, 2016, 9, 2037.

15 (a) J. M. Tukacs, M. Novák, G. Dibó and L. T. Mika, Catal. Sci. Technol., 2014, 4, 2908; (b) A. Dutta Chowdhury, R. Jackstell and M. Beller, ChemCatChem, 2014, 6, 3630.

16 (a) W. Li, J. Xie, H. Li and Q. Zhou, Green Chem., 2012, 14, 2388; (b) J. Deng, Y. Wang, T. Pan, Q. Xu, Q. Guo and Y. Fu, ChemSusChem, 2013, 6, 1163; (c) S. Wang, H. Huang, V. Dorcet, T. Roisnel, C. Bruneau and C. Fischmeister, Organometallics, 2017, 36, 3152.

17 Y. Yi, H. Liu, L.-P. Xiao, B. Wang and G. Song, ChemSusChem, 2018, 11, 1474.

18 H. Mehdi, V. Fábos, R. Tuba, A. Bodor, L. T. Mika and I. T. Horváth, Top. Catal., 2008, 48, 49.

19 F. M. A. Geilen, B. Engendahl, A. Harwardt, W. Marquardt, J. Klankermayer and W. Leitner, Angew. Chem., Int. Ed., 2010, 49, 5510.

20 J. M. Tukacs, D. Király, A. Strádi, G. Novodarszki, Z. Eke, G. Dibó, T. Kégl and L. T. Mika, Green Chem., 2012, 14, 2057.

21 L. Deng, J. Li, D. M. Lai, Y. Fu and Q.-X. Guo, Angew. Chem., Int. Ed., 2009, 48, 6529.

22 V. Fábos, L. T. Mika and I. T. Horvath, Organometallics, 2014, 33, 181.

23 S. Wang, V. Dorcet, T. Roisnel, C. Bruneau and C. Fischmeister, Organometallics, 2016, 36, 708.

24 G. Amenuvor, B. C. E. Makhubela and J. Darkwa, ACS Sustainable Chem. Eng., 2016, 4, 6010.

25 N. K. Oklu and B. C. E. Makhubela, Inorg. Chim. Acta, 2018, 482, 460 .

26 G. Amenuvor, J. Darkwa and B. C. E. Makhubela, Catal. Sci. Technol., 2018, 8, 2370.

27 C. A. M. R. van Slagmaat and S. M. A. De Wildeman, Eur. J. Inorg. Chem., 2018, 6, 694.

28 H. M. Jung, S. T. Shin, Y. H. Kim, M.-J. Kim and J. Park, Organometallics, 2001, 20, 3370.

29 B. L. Conley, M. K. Pennington-Boggio, E. Boz and T. J. Williams, Chem. Rev., 2010, 110, 19.

30 C. P. Casey and H. Guan, Organometallics, 2012, 31, 2631.

31 C. P. Casey, S. Singer, D. R. Powell, R. K. Hayashi and M. Kavana, J. Am. Chem. Soc., 2001, 123, 1090 (ref. 54.

32 Y. Shvo and D. Czarkie, J. Organomet. Chem., 1986, 315, C25.

33 M. K. Thorson, K. L. Klinkel, J. Wang and T. J. Williams, Eur. J. Inorg. Chem., 2009, 2, 295.

34 (a) A. Tlili, J. Schranck, H. Neumann and M. Beller, Chem. - Eur. J., 2012, 18, 15935; (b) S. Zhou, S. Fleischer, K. Junge and M. Beller, Angew. Chem., Int. Ed., 2011, 50, 5120; (c) S. Fleischer, S. Werkmeister, S. Zhou, K. Junge and M. Beller, Chem. - Eur. J., 2012, 18, 9005; (d) S. Fleischer, S. Zhou, S. Werkmeister, K. Junge and M. Beller, Chem. Eur. J., 2013, 19, 4997; (e) S. Zhou, S. Fleischer, H. Jiao, K. Junge and M. Beller, Adv. Synth. Catal., 2014, 356, 3451; (f) K. Natte, W. Li, S. Zhou, H. Neumann and X. F. Wu, Tetrahedron Lett., 2015, 56, 1118.

35 (a) S. A. Moyer and T. W. Funk, Tetrahedron Lett., 2010, 51, 5430; (b) A. Pagnoux-Ozherelyeva, N. Pannetier, M. D. Mbaye, S. Gaillard and J.-L. Renaud, Angew. Chem., Int. Ed., 2012, 51, 4976; (c) D. S. Merel, M. Elie, J. F. Lohier, S. Gaillard and J.-L. Renaud, ChemCatChem, 2013, 5, 2939; (d) B. Emayavaramban, M. Roy and B. Sundararaju, Chem. Eur. J., 2016, 22, 3952.

36 T. Pasini, G. Solinas, V. Zanotti, S. Albonetti, F. Cavani, A. Vaccari, A. Mazzanti, S. Ranieri and R. Mazzoni, Dalton Trans., 2014, 43, 10224-10234.

37 (a) P. J. Stevens, F. J. Devlin, C. F. Chablowski and M. J. Frisch, J. Phys. Chem., 1994, 98, 11623; (b) A. D. Becke, J. Chem. Phys., 1993, 98, 5648.

38 (a) P. J. Hay and W. R. Wadt, J. Chem. Phys., 1985, 82, 299; (b) S. Huizinga, J. Anzelm, M. Klobukowski, E. RadzioAndzelm, Y. Sakai and H. Tatewaki, Gaussian Basis Sets for Molecular Calculations, Elsevier, Amsterdam, 1984.

39 (a) A. Comas-Vives, G. Ujaque and A. Lledós, Organometallics, 2007, 26, 4135; (b) A. Comas-Vives, G. Ujaque and A. Lledós, J. Mol. Struct.: THEOCHEM, 2009, 307, 123.

40 D. Hollmann, H. Jiao, A. Spannenberg, S. Bähn, A. Tillack, R. Parton, R. Altink and M. Beller, Organometallics, 2009, 28, 473.

41 R. S. Assary and L. A. Curtiss, Chem. Phys. Lett., 2012, 541, 21.

42 (a) C. P. Casey and J. B. Johnson, Can. J. Chem., 2005, 83, 1339; (b) C. P. Casey and J. B. Johnson, J. Am. Chem. Soc., 2005, 127, 1883; (c) C. P. Casey, J. B. Johnson, S. W. Singer and Q. Cui, J. Am. Chem. Soc., 2004, 127, 3100.

43 (a) S. Moulin, H. Dentel, A. Pagnoux-Ozherelyeva, S. Gaillard, A. Poater, L. Cavallo, J.-F. Lohier and J.-L. Renaud, Chem. - Eur. J., 2013, 19, 17881; (b) T.-T. Thai, D. S. Mérel, A. Poater, S. Gaillard and J.-L. Renaud, Chem. Eur. J., 2015, 21, 7066.

44 (a) B. Xu, S.-F. Zhu, Z.-C. Zhang, Z.-X. Yu, Y. Ma and Q.-L. Zhou, Chem. Sci., 2014, 5, 1442; (b) Y.-Y. Ren, S.-F. Zhu and Q.-L. Zhou, Org. Biomol. Chem., 2018, 16, 3087.

45 K. Hopmann, Chem. - Eur. J., 2015, 21, 10020.

46 ISO 14044: 2006, Environmental Management - Life Cycle Assessment - Requirements and Guidelines, International Organization for Standardization, 2006.

47 (a) D. Kralisch, D. Ott and D. Gericke, Green Chem., 2015, 17, 123; (b) V. Isoni, D. Kumbang, P. N. Sharratt and H. H. Khoo, J. Environ. Manage., 2018, 214, 267.

48 (a) H. H. Khoo, W. L. Ee and V. Isoni, Green Chem., 2016, 18, 1912; (b) R. Mazzoni, C. Cesari, V. Zanotti, C. Lucarelli, T. Tabanelli, F. Puzzo, F. Passarini, E. Neri, G. Marani, R. Prati, F. Viganò, A. Conversano and F. Cavani, ACS Sustainable Chem. Eng., 2019, 7, 224. 
49 (a) Z. Wang, Z. Li, T. Lei, M. Yang, T. Qi, L. Lin, X. Xin, A. Ajayebi, Y. Yang, X. He and X. Yan, Appl. Energy, 2016, 183, 170; (b) M. A. F. Delgove, A. B. Laurent, J. M. Woodly, S. M. A. De Wildeman, K. V. Bernaerts and Y. van der Meer, ChemSusChem, 2019, 12, 1349.

50 (a) C. Koroneos, A. Dompros, G. Roumbas and N. Moussiopoulos, Int. J. Hydrogen Energy, 2004, 29, 1443; (b) S. Rivas, A. M. Raspolli-Galletti, C. Antonetti, V. Santos and J. C. Parajó, J. Wood Chem. Technol., 2015, 35, 315.

51 R. Arvidsson, A.-M. Tillman, B. A. Sandén, M. Janssen, A. Nordelöf, D. Kushnir and S. Molander, J. Ind. Ecol., 2018, 22, 1286.

52 H. H. Khoo, L. L. Wong, J. Tan, V. Isoni and P. Sharratt, Resour., Conserv. Recycl., 2014, 95, 174.

53 Environmental Product Declaration (EPD) - PCR Basic Module - Basic Chemicals CPC 34 (v3.0), 2017.

54 M. Fauré, C. Saccavini and G. Lavigne, Chem. Commun., 2003, 1578.

55 (a) H. Remy, Z. Anorg. Allg. Chem., 1924, 137, 365; (b) W. P. Griffith, Platinum Metals Rev., 1975, 19, 60.

56 P. Nuss and M. J. Eckelman, Met. Environ. Impacts, 2014, 9, e101298.

57 C. Cesari, L. Sambri, S. Zacchini, V. Zanotti and R. Mazzoni, Organometallics, 2014, 33, 2814.

58 D. X. Klein, T. A. Girard and H. R. Johnson; assignors to Heyden Chemical Corporation, New York, N.Y., a corporation of Delaware, US2658920, 1951.

59 J. Safari, N. M. Arani and A. R. Esfahani, Asian J. Chem., 2011, 23(6), 495-498.
60 K.-V. Tran and D. Bickar, J. Org. Chem., 2006, 71, 6640.

61 R. Adams and A. F. Thal, Benzyl cyanide, Org. Synth., 1922, 2, 59, collective vol. 1, p36.

62 R. Adams and A. F. Thal, Benzyl cyanide, Org. Synth., 1922, 2, 9, collective vol. 2, p63.

63 (a) J. Y. Bae, S-H. Park, W-X. Cai and J-H. Zhen, Preparation of glycol ether (line 0027), JPH07206744A, 1995;

(b) H. W. Richardson, Copper Compounds, Ullmann's Encyclopedia of Industrial Chemistry, Wiley-VHC, Weinheim, 2005; (c) G. Zhou, L. Feng, Q. Sun, A. Wang, T. Song and Q. Qi, The method of producing high selectivity triethylamine (example 4, line 0060-0062), CN104370748B, 2016.

64 (a) M. I. Bruce and J. R. Knight, J. Organomet. Chem., 1968, 12, 411; (b) B. A. Persson, A. L. E. Larsson, M. Le Ray and J.-E. Bäckvall, J. Am. Chem. Soc., 1999, 121, 1645.

65 M. J. Mays, M. J. Morris, P. R. Raithby, Y. Shvo and D. Czarkie, Organometallics, 1989, 8, 1162.

66 O. Jolliet, M. Margni, R. Charles, S. Humbert, J. Payet, G. Rebitzer and R. Rosenbaum, Int. J. Life Cycle Assess., 2003, 8, 324.

67 Fifth Assessment Report, The Physical Science Basis, Intergovernmental Panel on Climate Change, 2013.

68 (a) J. H. Choi, N. Kim, Y. J. Shin, J. H. Park and J. Park, Tetrahedron Lett., 2004, 45, 4607; (b) D. G. Hanna, S. Shylesh, P. A. Parada and A. T. Bell, J. Catal., 2014, 311, 52; (c) D. He and I. T. Horváth, J. Organomet. Chem., 2017, $847,263$. 